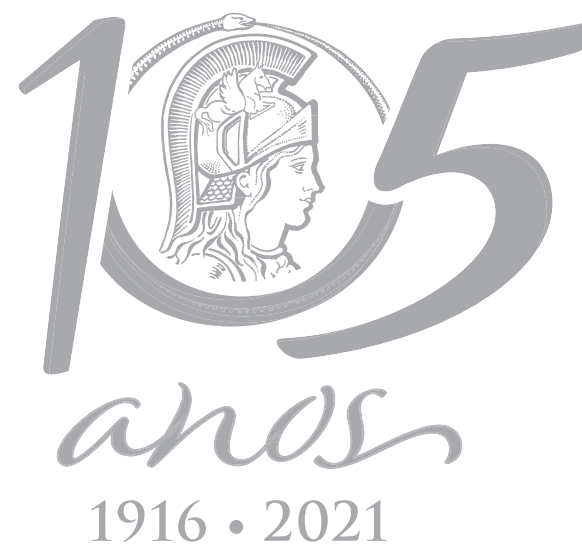

\title{
Mechanical and electrical properties of MWCNTs - high early strength cement - mortars composite: Dispersion of CNTs and effect of chemical admixtures
}

\author{
VIICTOR J. GARCÍA, CARMEN O. MÁRQUEZ, ALONSO R. ZÚÑIGA-SUÁREZ, \\ BERENICE C. ZÚÑIGA-TORRES \& PEDRO J. RÍOS-GÓNZALEZ
}

\begin{abstract}
The objectives of this research were to study (1) the dispersion of MWCNTS in an aqueous system by three commercial admixtures (CAds) for concrete, and (2) the effect of CAds and MWCNTS on indirect tensile strength and electrical conductivity of MWCNTs-high early strength (HE) cement-mortar composites. To achieve the objectives, we dispersed MWCNTs in an aqueous system with (1) hydroxylated polymers-based water reducing plasticizer (HPs), a nonionic compound, (2) Naphthalene based superplasticizer (SNF), an anionic compound, and (3) calcium chloride-based accelerating agent (CC) a neutral amphoteric salt. We prepared a total of 242 samples grouped in three sets: (1) Plain mortar [PM] (water + HE cement + Sand), (2) [PM+CAd], and (3) [PM+CAd+MWCNTs]. The three CAds dispersed MWCNTs in an aqueous solution. The CC and HPs admixtures have a two-time bigger dispersing power than the SNF. They demand half of SNF's ultrasound energy for optimal dispersion. Although the SNF (anionic) based superplasticizer resulted incompatible with the $\mathrm{HE}$ cement, it improved the indirect tensile strength of [PM+SNF+MWCNTs] composite. In contrast, the CC (amphoteric) based accelerating agent was compatible with the HE cement; the CC adsorption on the MWCNTs surface favors an improvement in the electrical conductivity of [PM+CAd+MWCNTs] composite.
\end{abstract}

Key words: MWCNT, cement-based materials, high early strength cement, chemical admixtures, indirect tensile strength.

\section{INTRODUCTION}

Carbon nanotubes (CNTs) exhibit extraordinary properties suitable to advance new materials for many engineering applications. CNTs are molecules of carbon atoms in a periodic hexagonal structure, constituting a folded graphene sheet that forms a hollow cylinder (Segawa et al. 2016). A single hollow cylinder of carbon atoms forms a single wall CNT (SWCNT). In contrast, hollow concentric cylinders form a multiwall CNT (MWCNT). Thirty years have passed since the CNTS discover (Iijima 1991).
Nowadays, there is a considerable amount of scientific reports regarding CNT applications in the construction industry (Bautista-Gutierrez et al. 2019, Evangelista et al. 2019, Rashad 2017). Cement-based materials (CBMs) doped with CNTs display new and enhanced mechanical properties, self-control of crack propagations, and high electrical conductivity, among other improvements (Sanchez \& Sobolev 2010). However, several unsolved issues still limiting the application of CNTs in the construction industry. The CNTs' price/Improvement ratio 
still high enough to limit practical applications. Therefore, new advances are needed lowering the CNTs' price and increasing the magnitude of improvement (MOI). Although more research is needed to reduce CNTs' prices, the chemical vapor deposition method has shown the most promise in its price/unit ratio (Siddique \& Mehta 2014). The increase of the MOI still been a challenge, mainly because there are several types of portland cement and three interactions to be engineered; (1) the interaction between the dispersing agent's molecule and the cement particles, (2) between cement particle and CNTs, and (3) between dispersing agent's molecule and CNTs. When the dispersing agent is a commercial CAd for concrete, the interaction between the dispersing agent's molecule and the cement particles is "known," but few understood (Kurdowski 2014). It is the base of a huge industry directed to reduce the cost and increase the functionality of concrete construction. However, more studies are needed, considering the compatibility of the CAd and the type of cement.

The interaction of CNTs-cement components involves studying CNTs' effect on cement components hydration (Alafogianni et al. 2019, Makar \& Chan 2009). While the interaction between the dispersing agent's molecule and CNTs has been a hot research topic during the last two decades. Few studies are regarding the use of CAd for concrete as CNTs dispersing agents. Fewer studies are dealing with the consequences of the interaction between the CAd molecules and the CNTs. Notably, the engineering of the interaction between CAd molecules and the CNTs remains an issue to overcome.

A central challenge overcoming this issue is the homogeneous dispersion of the CNTs in the CBM matrix. A well-accepted and practical method includes the use of ultrasound to disentangle CNTs bundles in an aqueous solution and the use of a dispersing agent to disperse CNTs (Konsta-Gdoutos et al. 2010, Yu et al. 2007), and the optical absorption spectroscopy to control CNTs dispersion degree (Alafogianni et al. 2016). Previous studies have shown that if the ultrasound source's mechanical energy is very high, the physical integrity of the CNTs is affected. Thus, those properties that depend on aspect ratio will be affected. The electrical conductivity is affected by an increase in the number of CNTS needed to reach the percolation threshold. While if the energy delivered is too low, the degree of CNTs disentanglement is low.

Similarly, the CNT clusters become defects that adversely affect the properties of the CBM. The minimum energy required for CNTs disentanglement in an aqueous solution depends on the amount of CNTs, the type and the quantity of the dispersing agent, and the dispersing agent's dispersion power. Many studies in the literature reported on the minimum energy required to disentangle CNTs in an aqueous solution with a dispersing agent dissolved in it. However, few studies reported the energy required to separate CNTs in aqueous solutions with CAd. The dispersing agent must be adsorbed on the surface of the CNTs to disperse CNTs homogeneously in solution. However, the dispersing agent's molecular structure, molecular size, and the electrostatic characteristic of their functional groups largely determine the interaction between CNTs and the dispersing agent's molecule and the improvement in the properties of the CBM. Despite many studies reports on the dispersion power of a large number of dispersing agents (Rashad 2017), few studies reported on CNTs dispersion power of CAd for concrete.

Previous researchers have shown evidence of CNTs' ability to improve the mechanical properties of CBM. Evangelista et al. (2019) found 
that the addition of 0.4 wt\% of CNTs to CBM increases compression, tensile, flexural strength by $40 \%, 30 \%$, and $15 \%$, respectively. The addition of low amounts of CNTs enhances fracture behavior by bridging micro-cracks and delaying their propagation; increases fracture strength, toughness, and the flexural toughness index (Alafogianni et al. 2019). Hawreen \& Bojas (2019) reported that the addition of CNTs caused a reduction in the initial and long-term shrinkage of CBM up to $54 \%$ and $15 \%$, respectively. The authors reported that the CNTs-CBM composite shows a 17\%-18\% lower long-term creep than the plain CBM. Sedaghatdoost \& Behfarnia (2018) reported that $0.1 \mathrm{wt} \%$ MWCNTs incorporation in CBM improved compression, tensile, and flexural strength by $35 \%, 8 \%$, and $11.2 \%$, respectively. Lushnikova \& Zaoui (2017) used molecular dynamics simulation to study the effect of CNTs incorporation into CBM. The authors reported that the shear modulus, bulk modulus, elastic constants, and Poisson ratio improved upon CNTs incorporation.

Campillo et al. (2003) reported that CNTs improved cement samples' compressive strength for the first time. Makar et al. (2005) observed MWCNTs crack bridging and fiber pull-out and concluded that it is due to strong bonding between the CNTs and the cement matrix. Li et al. (2005) found that cement hydration products coated CNTs in composite materials while exhibited good compressive and flexural strength. They also found that MWCNTs improved the pore structure of the cement matrix. Sáez de Ibarra et al. (2006) reported that MWCNTS+CBM composites exhibited better mechanical properties than displayed by the SWCNTS+CBM composites. Kowald et al. (2008) compared untreated MWCNTs-, and oxidized MWCNTs-cements composites and concluded that untreated MWCNTS improve low hardened C-S-H content while oxidized MWCNTs increases contents of high hardened $\mathrm{C}-\mathrm{S}-\mathrm{H}$. Hunashyal et al. (2011) found that a low amount of MWCNTs (between 0.25 and 0.75 wt \%) increased the flexural strength by $30 \%$ to $45 \%$, and increasing the MWCNTs content to 1 wt\% decreased the flexural strength. Wang et al. (2013) found that treated CNTs improve the flexural strength and Portland cement composite's compressive strength. They reported that MWCNTs acted as bridges and made networks across crack and voids and suggested a strong bonding between the CNTs and the cement matrix. Wang et al. (2015) stated as an existing problem, the issue of compatibility among CNTs and CBM as well as CNTs and dispersants used.

However, few reports are regarding the compatibility between cement and CAd, cement and CNTs, and between the CAd and CNTs. Fewer reports are considering the indirect tensile strength of CNTs-CBM composites. A considerable amount of reports deals only with ordinary Portland cement. They do not report on the compatibility issue between the type of cement and CAds. Moreover, few reports are on CAd-CNT interaction, which governs the relative improvement in the composite's mechanical properties. The mechanical properties of CNTs+CBM composites depend mainly on the bond's strength between the CAd and CNTs. The CAd-cement particle interaction depends on the compatibility of the CAd with the cement. It may depend on the interference of the CAd with the hydration of the different phases of the cement.

Electrical conductivity represents a material's ability to conduct electric current to a given temperature. The electrical conductivity of CBM is a fundamental property in applications like electrical grounding, lightning protection, resistance heating, static charge dissipation, electromagnetic interference shielding, cathodic protection, and thermoelectric energy generation (chung 
2004). The electrical conductivity of CNTs-CBM composite sparks an interest in engineering materials by CNTs addition in "smart" sensing applications. Previous reports indicate that the conductivity of CBM improved by adding CNTS (Yoo et al. 2019). There are many reports on the electrical conductivity of CNTs-CBM composites (Demarchi \& Tagliaferro 2015, Rashad 2017). The most effective way to achieve high electrical conductivity values in CNTS-CBM composites is by increasing the load of CNTs. However, while an increase of the CNTs concentration improves the electrical conductivity, it simultaneously affects the thermal and mechanical properties of the composite (Jagdale et al. 2015). Therefore, there is a need for more research to increase electrical conductivity without significantly affecting other properties. There are few reports on how commercial CAds for concrete affects the electrical conductivity of CNTs-CBM composites. Advances in engineering CNTs-CBM composites, particularly in "smart" sensing technology, depend not only on CAd's work but also in uncovering the functioning and the contribution of the main actors' electrical conductivity (CAds, CNTs, cement, aggregates).

Interestingly, in CBM could exist different electrical conductivity regimens, electronic and ionic as well. CNTs could work as an electronic highway for electrons and as an ionic highway for ions trapped inside the CNTs. The ionic conduction by CNTS is a research topic in Lithium batteries, where electrodes made of CNTs are promising materials (Han et al. 2020). The first one is a central property in the "smart" sensing application of CNTs-CBM composites. However, the CNT's surrounding environment and the ability to change the conductivity under stress/ strain are important (Jagdale et al. 2015).

This research aimed to study: (1) the dispersion of MWCNTS by three commercial CAds for concrete in an aqueous system, and
(2) the effect of CAds and MWCNTs on indirect tensile strength and electrical conductivity of MWCNTS-HE cement-mortar composites. MWCNTS were dispersed in an aqueous solution to study the CAd and CAd+MWCNTs' effect on the [PM+CAd+MWCNTs] composite's mechanical and electrical properties.

\section{MATERIALS AND METHODS}

Figure 1 shows an illustrative flowchart depicting the essential stages in this study: (1) Optimization of parameters for homogeneous dispersion of CNTs in aqueous solution. (2) Preparation of a HE cement-mortar sample. (3) Mechanical and electrical conductivity properties characterization. The first stages involve the optimization of sonication parameters and the weight of CAd for homogeneous dispersion of CNTs in an aqueous solution. The second stages comprise the preparation of three sets of discshaped samples and three sets of rectangular prism-shaped samples: (1) Plain mortar [PM]. (2) Plain mortar with a CAd [PM+CAd]. (3) Plain mortar with a CAd and MWCNTs added $[P M+C A d+M W C N T s]$. The third stages involve measuring the indirect tensile strength (Brazilian test) and the electrical conductivity through the direct-current four-pole method.

\section{Materials}

A hydraulic cement type HE (high early-strength cement) by Holcim Ecuador S.A. (Latacunga, Ecuador) was used to prepare MWCNTS-HE cement-mortar composite. Table I shows the chemical and mineral composition and the specific surface area of the HE cement.

Timesnano, a subsidiary of Chengdu Organic Chemical Co. Ltd., Chinese Academy of Sciences, PR China, provided the MWCNTs used in this study. Table II shows the properties of MWCNTs, 


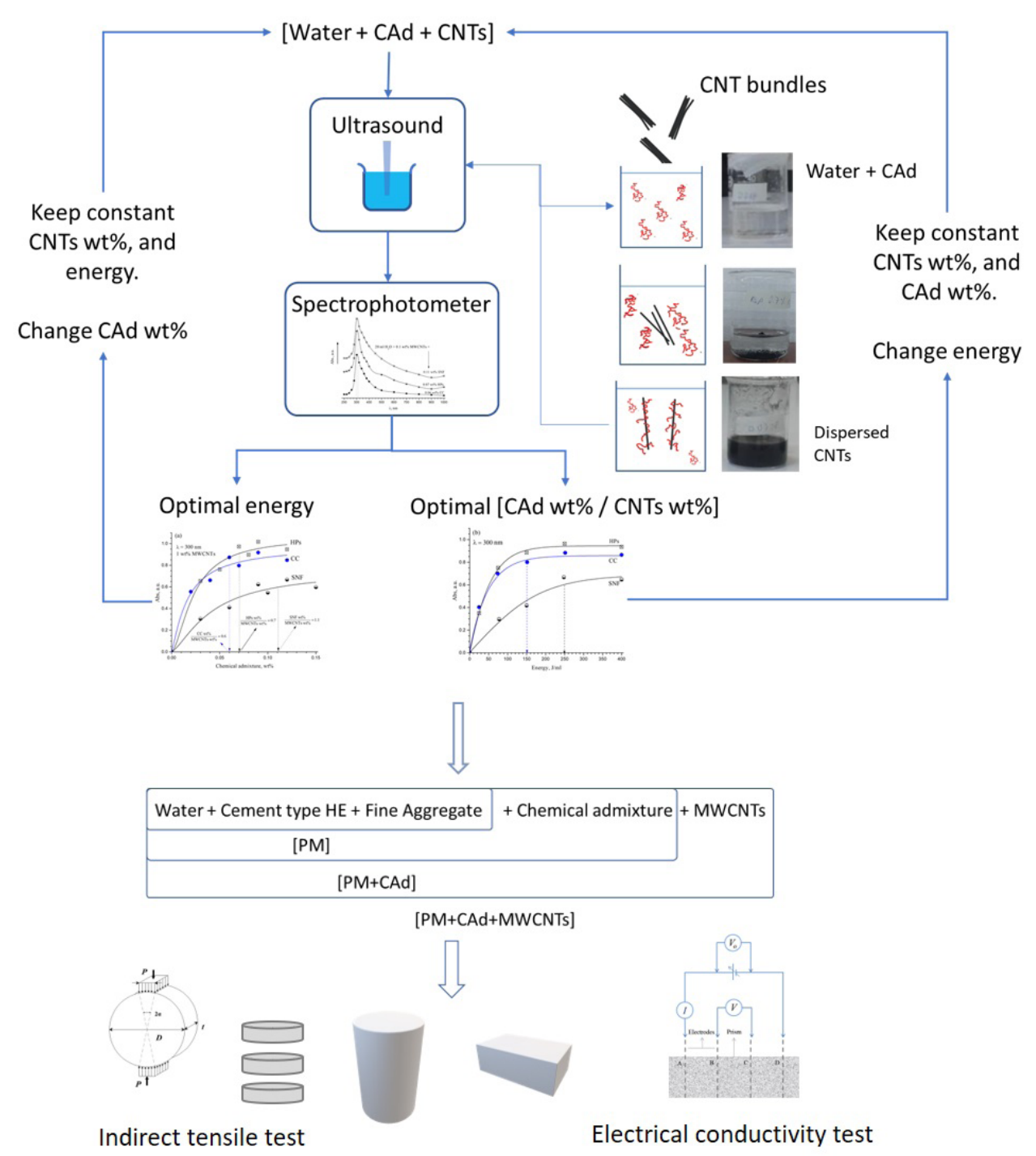

Figure 1. Flowchart depicting the essential stages in this study.

and Figure 2 shows the morphological attributes of MWCNTS.

ADITEC Ecuadorian Cia. Ltda (Durán, Guayas, Ecuador) provided the three CAds used in this study. CAd stabilized the MWCNTs dispersion and prevented the re-aggregation of the nanotubes in water (Table III).

\section{Mixture proportions}

Table IV shows the raw material proportions in the plain mortar mixture preparation. We prepared a PM and MWCNT-mortar composite following the Ecuadorian standards NTE-INEM 155:2009
(NTE-INEM 2009) and NTE-INEM 2563:2011(NTEINEM 2011). Table IV shows the main aggregate characteristics, design specification, and the amount of raw material needed to fabricate one cubic meter of mortar.

This study used disc-shaped samples with a thickness of $25 \mathrm{~mm}$ for the indirect tensile test (Brazilian test) gotten after cutting cylindrical specimens ( $50 \mathrm{~mm}, 100 \mathrm{~mm}$ ) prepared with fresh mortar. Similarly, the electrical conductivity test carried out on rectangular prism-shaped samples ( $80 \mathrm{~mm} \times 20 \mathrm{~mm} \times 20 \mathrm{~mm}$ ) was made directly with fresh mortar in molds with the 
Table I. Chemical and mineral composition, and the Blaine specific surface area of the HE cement.

\begin{tabular}{|c|c|c|c|}
\hline Oxide & $\begin{array}{l}\text { Composition } \\
\text { (wt\%) }\end{array}$ & Mineral phase-Compound-Common name & $\begin{array}{c}\text { Composition } \\
\text { (wt\%) }\end{array}$ \\
\hline $\mathrm{CaO}$ & 64.4 & $3 \mathrm{CaO} . \mathrm{SiO}_{2}$ - Tricalcium silicate - $\left(\mathrm{C}_{3} \mathrm{~S}\right)$ & 59.4 \\
\hline $\mathrm{SiO}_{2}$ & 19.5 & $2 \mathrm{CaO} . \mathrm{SiO}_{2}-$ Dicalcium silicate - $\left(\mathrm{C}_{2} \mathrm{~S}\right)$ & 11.2 \\
\hline $\mathrm{Fe}_{2} \mathrm{O}_{3}$ & 3.7 & $3 \mathrm{CaO} \cdot \mathrm{Al}_{2} \mathrm{O}_{3}$ - Tricalcium aluminate $-\left(\mathrm{C}_{3} \mathrm{~A}\right)$ & 11.5 \\
\hline $\mathrm{SO}_{3}$ & 2.8 & $4 \mathrm{CaO} \cdot \mathrm{Al}_{2} \mathrm{O}_{3} \cdot \mathrm{Fe}_{2} \mathrm{O}_{3}-$ Tetracalcium aluminoferrite - $\left(\mathrm{C}_{4} \mathrm{AF}\right)$ & 9.9 \\
\hline $\mathrm{Al}_{2} \mathrm{O}_{3}$ & 6.0 & Calcium sulfate (CaSO4) & 3 \\
\hline MgO & 1.3 & Pozzolans and other compounds & 5 \\
\hline $\mathrm{NaO}_{2}+\mathrm{K}_{2} \mathrm{O}$ & 0.9 & Blaine specific surface area $\left(\mathrm{cm}^{2} / \mathrm{g}\right)$ & 4300 \\
\hline
\end{tabular}

same dimensions. After $24 \mathrm{~h}$, the specimens were removed from their mold and stored in a pool of water kept at $20{ }^{\circ} \mathrm{C}$ until the test date.

Table $V$ shows the sets of samples prepared with three different CAds, three different CAd/ cement loading ratios, and three different CNTs/ cement ratios. Therefore, this study involved testing 185 discs and 57 rectangular prisms.

\section{Dispersion of MWCNTs in aqueous solution}

Admixtures and ultrasound allowed the dispersion of MWCNTs in an aqueous solution. The CAd dispersibility was optimized through the CAd/MWCNTs loading ratio's optimal value and delivering the minimum energy $\left(E_{\min }\right)$ to minimize CNT damage.

The optical absorbance served as an indicator of dispersion quality. We used a UVVIS spectrometer (Jenwey ${ }^{\circledR}$ model 7305) and quartz cuvettes with an optical path of $10 \mathrm{~mm}$ measuring the absorbance. Distilled water was the aqueous medium in all the dispersion experiments.

An Ultrasonic Homogenizer Model JY96-IIN (Ningbo Scientz Biotechnology Co. Ltd, China) was used to deliver mechanical energy with a maximum power $P_{\max }$ of $150 \mathrm{~W}$ in a volume of 10 to $100 \mathrm{ml}\left(V_{m}=100 \mathrm{ml}\right)$. The Homogenizer works at $20-25 \mathrm{kHz}$ and has a titanium alloy cylindrical probe with a diameter of 1/4". Equation (1) allowed the calculation of the mechanical energy delivered per $\mathrm{ml}$ of suspension. In equation (1): $P_{\%}$ represents a power proportion of the maximum power. $D C_{\%}$ stands up for the duty cycle. The immersion depth of the cylindrical probe in the flask was $4 / 5$ of the total depth. The total working time, $t_{\text {max }}$, was 15 minutes in all the experiments.

$$
E\left[\frac{J}{m l}\right]=\frac{t_{\text {Total }}[\min ] P_{\max }[W] P_{\%} D C_{\%}}{V_{m}[m l]}\left(60\left[\frac{J}{\min W}\right]\right)
$$

The CAds concentration's effect on dispersion quality was studied by preparing solutions with different CAd/MWCNTs loading ratios. Then we find the optimal CAd/MWCNTs loading ratio required to avoid CAd stagnation or saturation. A low amount of CAd leads to partial CNTs disentanglement, whereas CAd excess introduces micelles in bulk (Dassios et al. 2015).

Determination of the optimal CAd/MWCNTs loading ratio comprised: (1) $20 \mathrm{ml}$ of water + 0.1 wt \% of MWCNT in a flask. (2) Add 0.2 wt\% of CAd. (3) set the ultrasonic Homogenizer to deliver $150 \mathrm{~J} / \mathrm{ml}$. (4) Measure optical absorption a 300 $\mathrm{nm}$ after the zero setting. (5) Repeat steps 1 to 4 while increasing the proportion of CAd in $0.2 \mathrm{wt}$ $\%$, each time until the absorbance value reaches 
Table II. Multiwall carbon nanotubes' properties.

\begin{tabular}{|c|c|c|c|}
\hline Inside diameter $(\mathbf{n m})$ & $\mathbf{5 - 1 0}$ & Outside diameter $(\mathbf{n m})$ & $\mathbf{2 0 - 4 0}$ \\
\hline Length $(\mu \mathrm{m})$ & $10-30$ & Aspect Ratio & $250-1500$ \\
\hline Purity $($ wt\%) & $>90$ & Elastic Modulus (TPa) & $0.8^{-0.9^{b}}$ \\
\hline Specific surface area $\left(\mathrm{m}^{2} / \mathrm{g}\right)$ & $>80$ & Tensile strength (GPa) & $11-63^{\mathrm{b}}$ \\
\hline Ash $($ wt\%) & $<8.0$ & Elongation at break $(\%)$ & $12^{\mathrm{b}}$ \\
\hline Bulk density $\left(\mathrm{g} / \mathrm{cm}^{3}\right)$ & 0.16 & & \\
\hline True density $\left(\mathrm{g} / \mathrm{cm}^{3}\right)$ & $\sim 2.1$ & Electrical conductivity ${ }^{\mathrm{c}}(\Omega \mathrm{m})^{-1}$ & $\sim 10^{5}$ \\
\hline Synthesis process & CVD (HiPCO NTs) & Thermal conductivity ${ }^{\mathrm{c}} \mathrm{W} /(\mathrm{mK})$ & $>3000$ \\
\hline
\end{tabular}

${ }^{a}$ Chemical vapor deposition; High-pressure disproportionation of CO. ${ }^{\text {b }}$ (Chen et al. 2011; Hilding et al. 2003). ' (D'Alessandro et al., 2016).

a plateau. The optimal CAd/MWCNTs ratio corresponds with a point where the absorbance reaches the plateau, or it is close to reaching its maximum value (Yu et al. 2007).

Determination of the minimum mechanical energy $\left(E_{\text {mim }}\right)$ to deliver to suspension in order to mitigate MWCNTS damage during exposure to acoustic waves (Chen et al. 2014) comprised:

(1) $20 \mathrm{ml}$ of water $+0.1 \mathrm{wt} \%$ of MWCNT in a flask.

(2) Add the proportion of CAd, such as the ratio CAd/MWCNT is to equal the optimal proportion. (3) set the ultrasonic Homogenizer to deliver an energy of $30 \mathrm{~J} / \mathrm{ml}$. (4) Measure optical absorption a $300 \mathrm{~nm}$ after the zero setting. (5) Repeat steps 1 to 4 while increasing the energy in $30 \mathrm{~J} / \mathrm{ml}$, each time until the absorbance value reaches a plateau. The mechanical energy to deliver for full dispersion and minimum damage to MWCNT corresponds with a point where the absorbance reaches the plateau, or it is close to reaching its maximum value. The zero setting involved the absorbance of a suspension of $\left[\mathrm{H}_{2} \mathrm{O}+\mathrm{CAd}\right]$ with the same amount of CAd used for preparing the $\left[\mathrm{H}_{2} \mathrm{O}+\mathrm{CAd}+\mathrm{MWCNT}\right]$ suspension (Grossiord et al. 2005). The beaker was positioned in a bath with ice to avoid temperature increases in the bulk solution. A temperature increases influence the dispersion efficiency. Therefore, the preparation of suspensions for the fabrication of the MWCNTcement mortar composites comprises the delivery of the minimum mechanical energy to bulk suspension and the optimal CAd/MWCNTs loading ratio.

\section{Indirect tensile test or Brazilian test}

Traditional Brazilian test demands cylindrical concrete samples, and its dimensions require the use of a relatively "large" quantity of material. However, nanomaterials are pricey even though they are used in low weight concentrations between 0.05 and 3\%. The improved Brazilian test by García et al. (2017) represents a simple, low-cost, robust, and effective characterization technique for MWCNTs-CBM composites.

In the Brazilian test, a compression load concentrated on a pair of antipodal points induces tensile stress in the direction perpendicular to de applied load (Figure 3) (García et al. 2017). The test usually ends with a sudden and violent failure of the specimen 


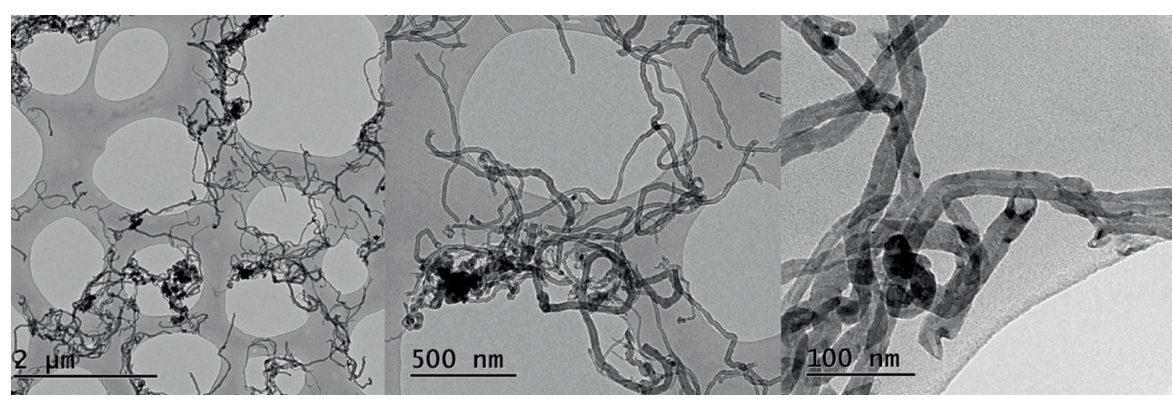

Figure 2.

Transmission electron microscope images of MWCNTs.

Table III. The chemical admixtures' most relevant properties.

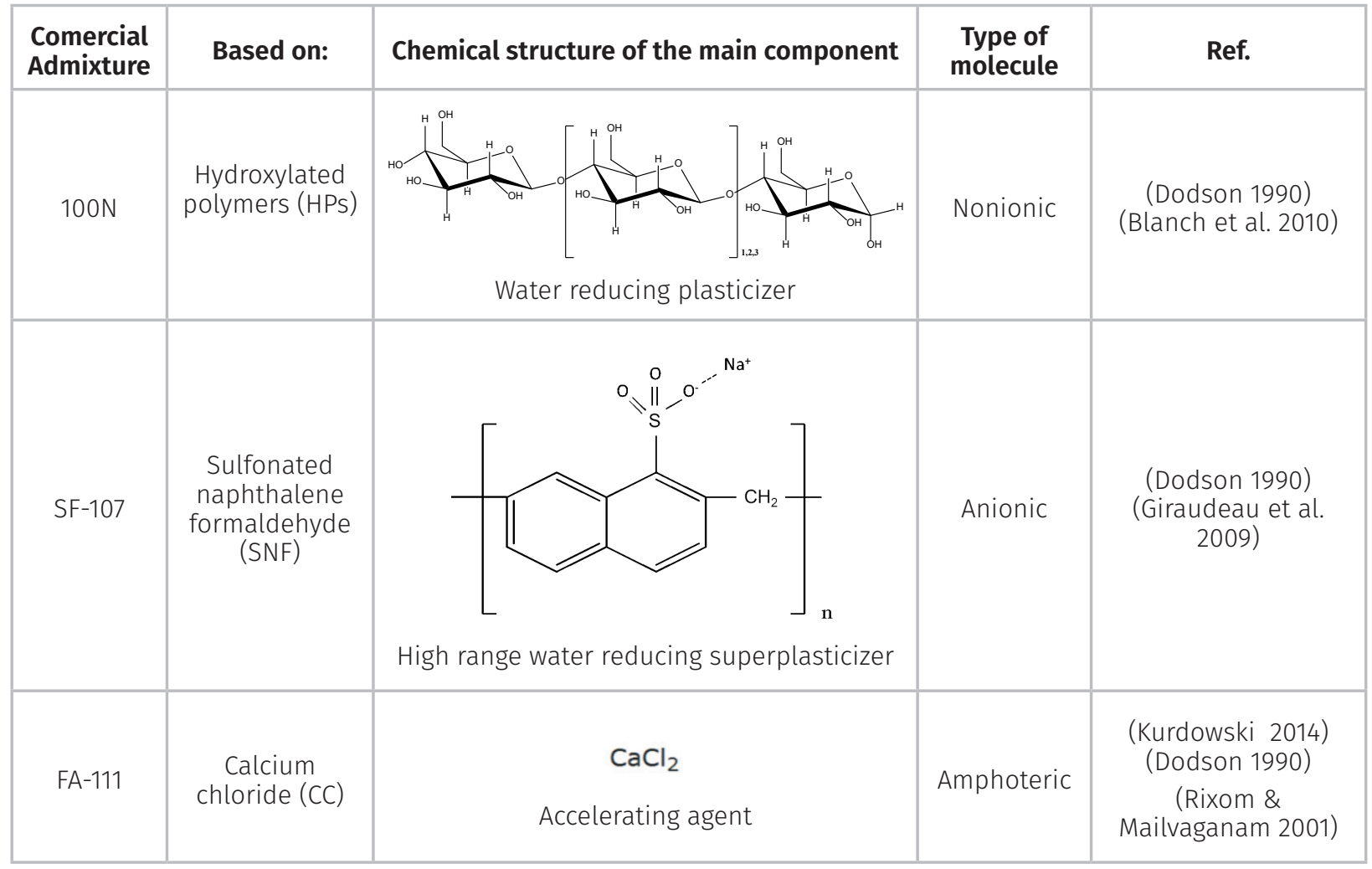

Table IV. The mixture proportions for the plain mortar, main aggregate characteristics, design's specification, and the amount of raw material needed to fabricate one cubic meter of mortar.

\begin{tabular}{|c|c|c|c|}
\hline & Quantity $/ \mathrm{m}^{3}$ & Characteristics & \\
\hline Water (l) & 240 & Fineness modulus (fine aggregate) & 2.69 \\
\hline Cement (kg) & 462 & Water absorption (\%) & 2.59 \\
\hline \multirow[t]{4}{*}{ Fine aggregate $(\mathrm{kg})$} & 1447 & Water/cement ratio & 0.52 \\
\hline & & Cement/fine aggregate ratio & 0.33 \\
\hline & & Compressive strength $f_{c}(\mathrm{MPa})$ & 21.00 \\
\hline & & Compressive strength $f_{\mathrm{c}}(\mathrm{MPa})$ at 7 days ${ }^{1}$ & 19.20 \\
\hline
\end{tabular}

${ }^{1}$ The value is the average of three cylinders tested. 
VÍCTOR J. GARCíA et al.

Table V. Sets of samples for the indirect tensile test and electrical conductivity test sample.

\begin{tabular}{|c|c|c|c|c|c|c|c|c|c|}
\hline \multicolumn{5}{|c|}{ Indirect tensile test -Brazilian test } & \multicolumn{5}{|c|}{ Electrical conductivity test } \\
\hline \multirow[t]{2}{*}{ Sample } & \multicolumn{2}{|c|}{ Admixture } & \multirow{2}{*}{$\begin{array}{c}\text { MWCNTs } \\
{\text { wt } \%{ }^{\mathrm{a}}}^{\text {MW }}\end{array}$} & \multirow[t]{2}{*}{ Disc } & \multirow[t]{2}{*}{ Sample } & \multicolumn{2}{|c|}{ Admixture } & \multirow{2}{*}{$\begin{array}{c}\text { MWCNTs } \\
{\text { wt } \%^{\mathrm{a}}}\end{array}$} & \multirow{2}{*}{$\begin{array}{c}\text { Rectangular } \\
\text { prism }\end{array}$} \\
\hline & Type & wt $\%^{a}$ & & & & Type & wt $\%^{a}$ & & \\
\hline PM & - & - & - & 5 & PM & - & - & - & 3 \\
\hline $\mathrm{PM}+\mathrm{CAd}$ & HPS & 0.3 & - & 5 & $\mathrm{PM}+\mathrm{CAd}$ & HPS & 0.24 & - & 3 \\
\hline$P M+C A d+C N T S$ & & 0.3 & 0.5 & 5 & $P M+C A d+C N T s$ & & 0.24 & 0.4 & 3 \\
\hline$P M+C A d+C N T S$ & & & 1 & 5 & $\mathrm{PM}+\mathrm{CAd}$ & & 0.48 & - & 3 \\
\hline $\mathrm{PM}+\mathrm{CAd}+\mathrm{CNTS}$ & & & 3 & 5 & $\mathrm{PM}+\mathrm{CAd}+\mathrm{CNTS}$ & & 0.48 & 0.8 & 3 \\
\hline$P M+C A d$ & & 0.6 & - & 5 & $P M+C A d$ & & 0.6 & - & 3 \\
\hline$P M+C A d+C N T S$ & & 0.6 & 0.5 & 5 & $P M+C A d+C N T s$ & & 0.6 & 1 & 3 \\
\hline$P M+C A d+C N T s$ & & & 1 & 5 & & & & & \\
\hline$P M+C A d+C N T s$ & & & 3 & 5 & & & & & \\
\hline $\mathrm{PM}+\mathrm{CAd}$ & & 1.8 & - & 5 & & & & & \\
\hline $\mathrm{PM}+\mathrm{CAd}+\mathrm{CNTS}$ & & 1.8 & 0.5 & 5 & & & & & \\
\hline$P M+C A d+C N T S$ & & & 1 & 5 & & & & & \\
\hline $\mathrm{PM}+\mathrm{CAd}+\mathrm{CNTS}$ & & & 3 & 5 & & & & & \\
\hline $\mathrm{PM}+\mathrm{CAd}$ & SNF & 0.55 & - & 5 & $P M+C A d$ & SNF & 0.44 & - & 3 \\
\hline $\mathrm{PM}+\mathrm{CAd}+\mathrm{CNTS}$ & & 0.55 & 0.5 & 5 & $\mathrm{PM}+\mathrm{CAd}+\mathrm{CNTS}$ & & 0.44 & 0.4 & 3 \\
\hline$P M+C A d+C N T S$ & & & 1 & 5 & $\mathrm{PM}+\mathrm{CAd}$ & & 0.88 & - & 3 \\
\hline $\mathrm{PM}+\mathrm{CAd}+\mathrm{CNTS}$ & & & 3 & 5 & $\mathrm{PM}+\mathrm{CAd}+\mathrm{CNTS}$ & & 0.88 & 0.8 & 3 \\
\hline$P M+C A d$ & & 1.10 & - & 5 & $P M+C A d$ & & 1.1 & - & 3 \\
\hline$P M+C A d+C N T S$ & & 1.10 & 0.5 & 5 & $P M+C A d+C N T S$ & & 1.1 & 1 & 3 \\
\hline$P M+C A d+C N T s$ & & & 1 & 5 & & & & & \\
\hline$P M+C A d+C N T S$ & & & 3 & 5 & & & & & \\
\hline$P M+C A d$ & & 3.30 & - & 5 & & & & & \\
\hline$P M+C A d+C N T S$ & & 3.30 & 0.5 & 5 & & & & & \\
\hline $\mathrm{PM}+\mathrm{CAd}+\mathrm{CNTS}$ & & & 1 & 5 & & & & & \\
\hline $\mathrm{PM}+\mathrm{CAd}+\mathrm{CNTS}$ & & & 3 & 5 & & & & & \\
\hline$P M+C A d$ & $\mathrm{CC}$ & 0.35 & - & 5 & $P M+C A d$ & $\mathrm{CC}$ & 0.28 & - & 3 \\
\hline$P M+C A d+C N T S$ & & 0.35 & 0.5 & 5 & $\mathrm{PM}+\mathrm{CAd}+\mathrm{CNTS}$ & & 0.28 & 0.4 & 3 \\
\hline$P M+C A d+C N T S$ & & & 1 & 5 & $P M+C A d$ & & 0.56 & - & 3 \\
\hline $\mathrm{PM}+\mathrm{CAd}+\mathrm{CNTS}$ & & & 3 & 5 & $\mathrm{PM}+\mathrm{CAd}+\mathrm{CNTS}$ & & 0.56 & 0.8 & 3 \\
\hline $\mathrm{PM}+\mathrm{CAd}$ & & 0.7 & - & 5 & $P M+C A d$ & & 0.7 & - & 3 \\
\hline $\mathrm{PM}+\mathrm{CAd}+\mathrm{CNTS}$ & & 0.7 & 0.5 & 5 & $P M+C A d+C N T s$ & & 0.7 & 1 & 3 \\
\hline$P M+C A d+C N T S$ & & & 1 & 5 & & & & & \\
\hline$P M+C A d+C N T S$ & & & 3 & 5 & & & & & \\
\hline$P M+C A d$ & & 2.1 & - & 5 & & & & & \\
\hline$P M+C A d+C N T S$ & & 2.1 & 0.5 & 5 & & & & & \\
\hline$P M+C A d+C N T S$ & & & 1 & 5 & & & & & \\
\hline $\mathrm{PM}+\mathrm{CAd}+\mathrm{CNTS}$ & & & 3 & 5 & & & & & \\
\hline
\end{tabular}

${ }^{a}$ Values expressed as a cement weight percentage. 
when the load reaches the value needed to spread an unstable crack (Carmona \& Aguado 2012). The induced stress field depends on the specimen's material properties and the loading geometry (Erarslan et al. 2012). García et al. (2017) reported that it is possible to reduce the loading geometry effect by using the experimental setup shown in Figure 3. Thus, equation (2) allowed the calculation of the indirect tensile strength $\left(\sigma_{\text {IтS }}\right)$.

$\sigma_{\text {ITS }}=\frac{2 P_{\max }}{\pi D t}\left[\frac{4 \sin \alpha\left(\sin ^{2} \alpha-3\right)^{2}}{3\left(8 \sin ^{3} \alpha+24 \sin \alpha-3 \sin 2 \alpha-6 \alpha\right)}\right]$

; $\alpha \geq 10^{\circ}$

In equation (2), $D$ represents the diameter of the disc, $t$ the thickness. $P_{\max }$ is the maximum value of the applied load when the disc fails and $\alpha$ is the angle supported by the contact area $\left(\alpha=12^{0}\right)$.

The Brazilian test was performed on a universal testing machine (Versa Tester by Soil Test Inc., USA) with a load cell of $5 \mathrm{kN}$, in the controlled displacement mode at a speed of $0.02 \mathrm{inch} / \mathrm{min}\left(8.47 \times 10^{-3} \mathrm{~mm} / \mathrm{s}\right)$.

\section{Electrical conductivity}

We used the direct-current four-pole method for measuring electrical resistivity of rectangular prism-shaped samples (80 mm x $20 \mathrm{~mm} \times 20$ $\mathrm{mm}$ ) with four metallic meshes embedded as electrodes conductivity (Han et al. 2007, KonstaGdoutos \& Aza 2014). Electrical conductivity is the
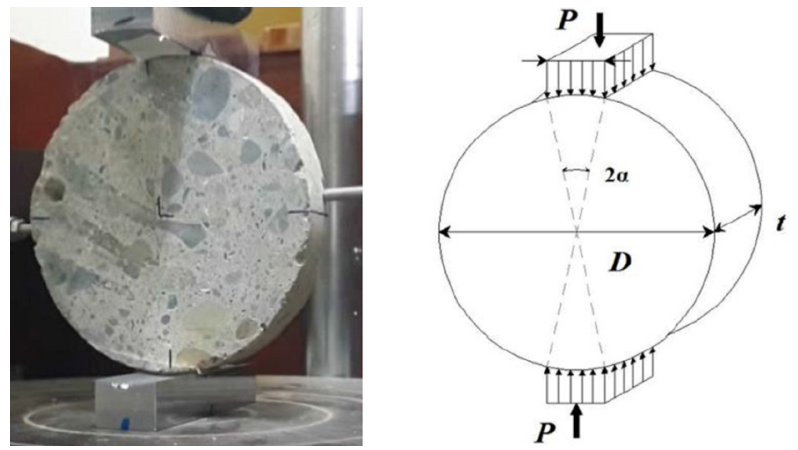

inverse of electrical resistivity. The mesh formed metal grids of $4 \times 4 \mathrm{~mm}$. The value of electrical conductivity $(\sigma)$ calculated from equation (3) is independent of the area of $\mathrm{B}$ and $\mathrm{C}$ electrodes, as well as the dimensions of the mesh (Figure 4) (B. Han et al. 2007). Thus, the direct-current four-pole method eliminates the influence of contact resistance and provides higher accuracy (Konsta-Gdoutos \& Aza 2014).

$\sigma=\frac{I}{V}\left(\frac{L}{S}\right)$

In equation (3), $V$ and I represent the voltage between electrodes $B$ and $C$ and the current flowing through electrodes $A$ and $D$, respectively (Figure 4). S and $L$ represent the specimen's crosssection and the distance between electrodes $B$ and $C$, respectively. We measured the electrical conductivity at $20{ }^{\circ} \mathrm{C}$.

The electrical conductivity measuring process comprises of direct-current four-pole method involves (1) application of voltage $V_{\text {o }}$ between electrodes $A$ and $D,(2)$ measurement of the voltage $(V)$ between electrodes B and C, (3) measurement of the current I flowing through electrodes A and D, and (4) calculation of the electrical conductivity from equation (6). We measured the electrical conductivity after seven days of curing at $20^{\circ} \mathrm{C}$.

\section{Electron microscopy}

The analysis of the MWCNTS morphological attributes was carried out using a TEM (JEM 2100F, JEOL Ltd. Tokyo, Japan). The sample preparation for TEM involved placing a few drops of solution on a carbon film Cu grid and dried in a vacuum desiccator for $48 \mathrm{~h}$. We used the SEM (DSM969A, ZEISS, Oberkochen, Germany) to obtain images of the fracture surface of the disc-shaped sample after the Brazilian test at seven days.

Figure 3. Experimental setup for the Brazilian test. 


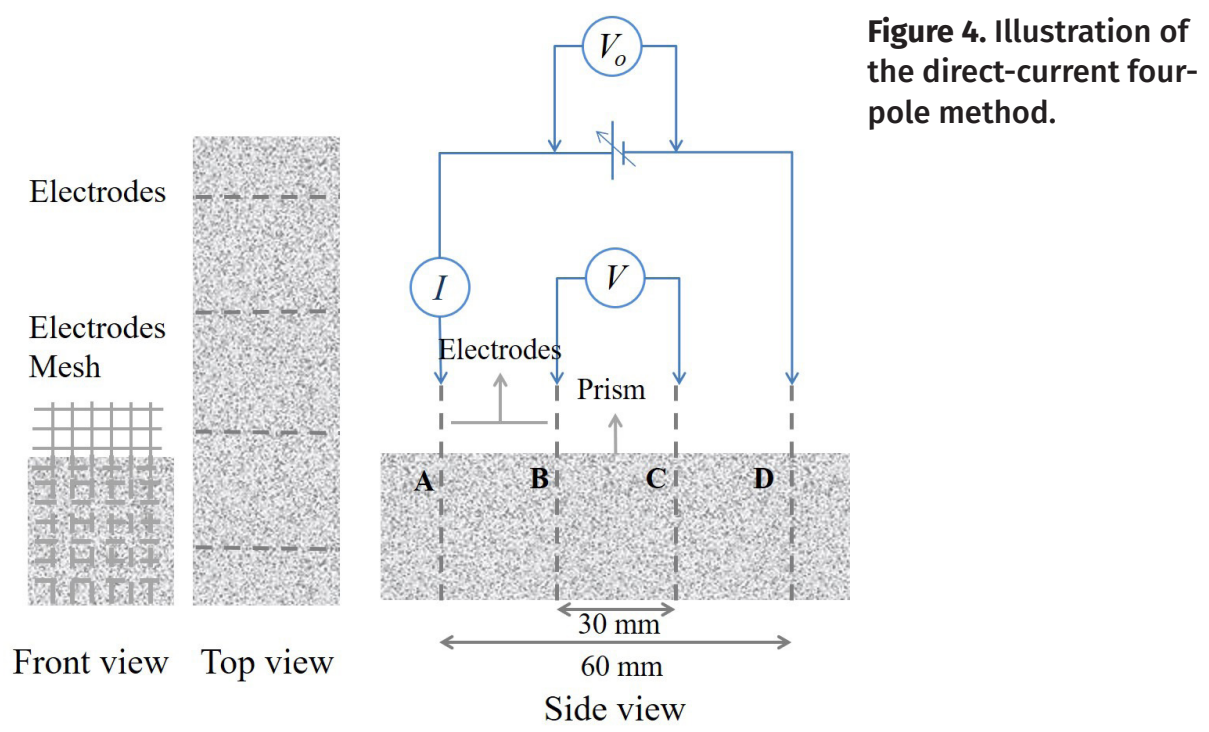

\section{Data processing and statistical analysis}

Statistical data processing was performed using Minitab ${ }^{\circledR} 17$ statistical software, State College, PA, USA. We generate descriptive data for the Indirect tensile strength and electrical conductivity; and carried out a Pearson's correlation analysis to assess the strength of the correlation between independent and dependent variables.

\section{RESULTS}

\section{Dispersion of MWCNTs in aqueous solution}

Individual CAd (SNF, HPS, and CC) are active in the UV-vis region and exhibit a maximum value of absorbance around $300 \mathrm{~nm}$ in aqueous solution $\left[\mathrm{H}_{2} \mathrm{O}+\mathrm{CAd}\right]$. Figure $5 \mathrm{a}$ shows the absorption spectra of $\left[\mathrm{H}_{2} \mathrm{O}+\mathrm{CAd}\right]$ solutions. Similarly, MWCNTS are active in the same region, and the $\left[\mathrm{H}_{2} \mathrm{O}+\mathrm{CAd}+\mathrm{MWCNTS}\right]$ spectra show a maximum of absorbance around $300 \mathrm{~nm}$. Figure 5b shows the absorption spectra of $\left[\mathrm{H}_{2} \mathrm{O}+\mathrm{CAd}+\mathrm{MWCNTS}\right]$ solutions. Although not presented, the corresponding absorption spectrum's intensity depends on the amount of MWCNTs individually dispersed in solution.
The CAd/MWCNTs ratios' measured values were 1.1, 0.6, and 0.7 for SNF, CC, and HPS, respectively (Figure $6 \mathrm{a}$ ). The $\mathrm{CC}$ and $\mathrm{HPS}$ are more efficient in dispersing MWCNTS than SNF. A CAd/MWCNTs ratio as low as 0.6 (CC) and 0.7 (HPs) is sufficient to separate the MWCNTs in aqueous media. The minimum energy required for optimal dispersion was 270, 150, and $150 \mathrm{~J} /$ $\mathrm{ml}$ for SNF, CC, and HPS, respectively (Figure 6b). Therefore, the CC and HPs required less energy for optimal dispersion than the SNF's energy.

\section{Indirect tensile strength}

The indirect tensile strength is related to the compression strength, water-cement ratio, and age of the concrete, among other factors (Zain et al. 2002). Figure 7a to 7c show the results of the indirect tensile test performed on the [PM], $[P M+C A d]$, and $[P M+C A d+M W C N T s]$ samples. Symbols represent the mean value of three samples, and the vertical segments are the standard deviation. The indirect tensile strength of [PM] samples averaged 3.85 MPa.

Figure 7a shows the indirect tensile strength of [PM+HPs] and [PM+HPS+MWCNTs] samples. The indirect tensile strength does not change with 
(a)

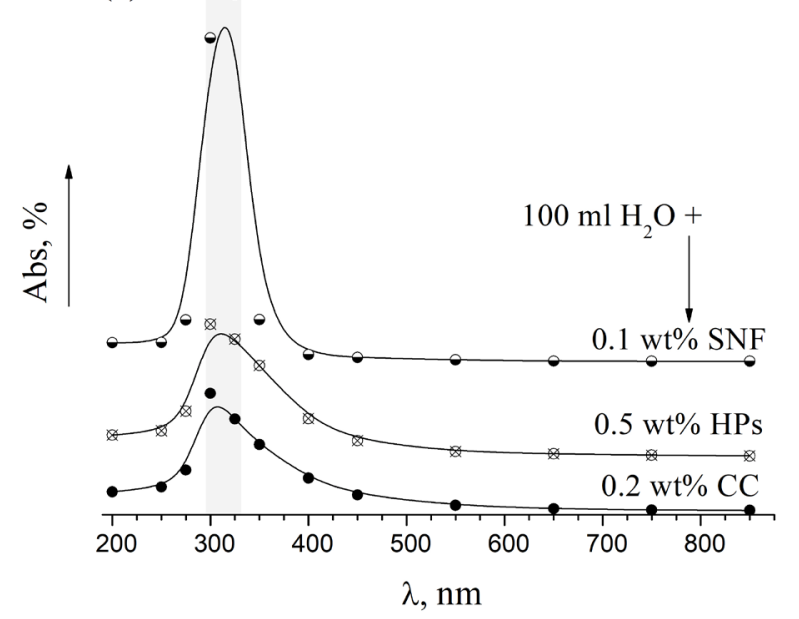

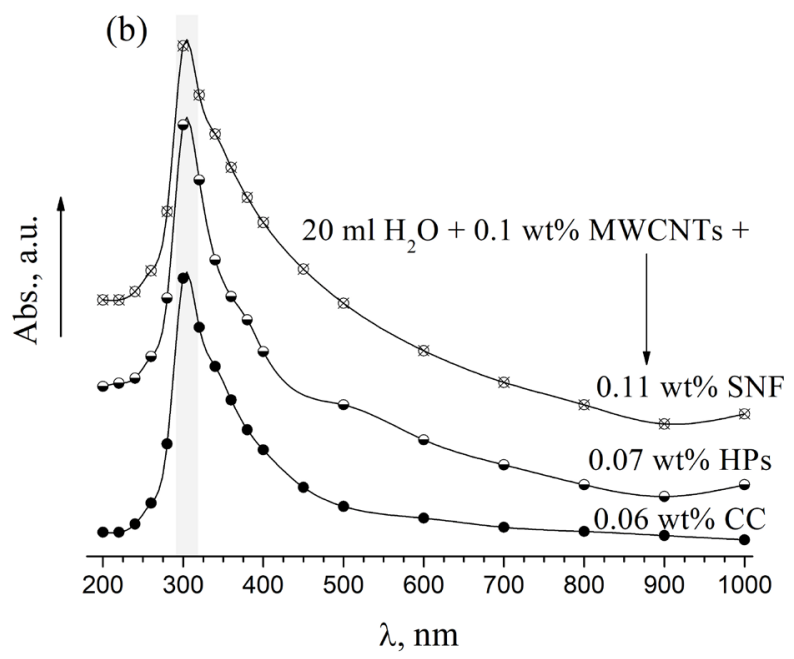

Figure 5. The optical absorption spectra of: (a) $\left[\mathrm{H}_{2} \mathrm{O}+\mathrm{CAd}\right]$ solutions, and $(\mathrm{b})\left[\mathrm{H}_{2} \mathrm{O}+\mathrm{CAd}+\mathrm{MWCNTs}\right]$ solutions.

(a)

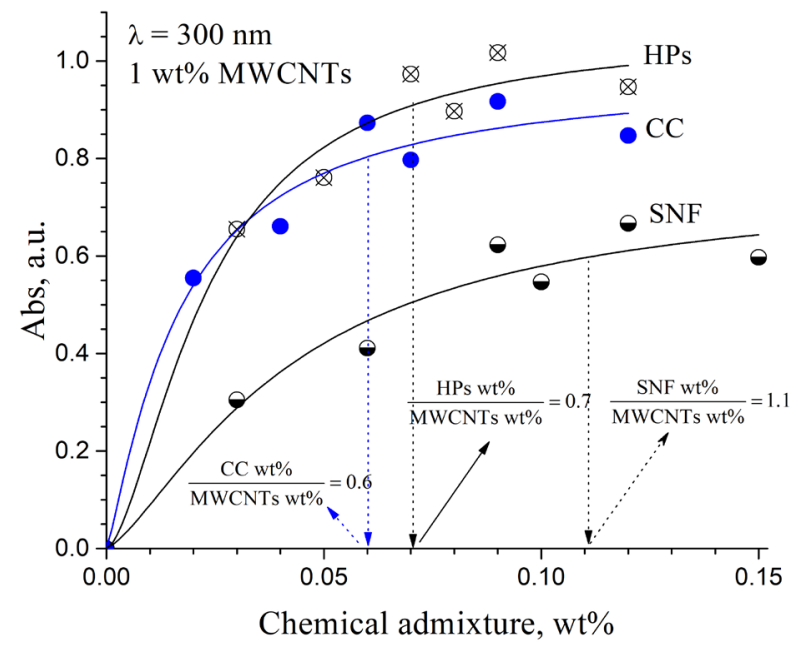

(b)



Figure 6. (a) The optimal values of the CAd/MWCNTs loading ratio. (b) The optimal amount of energy supplied to the $\left[\mathrm{H}_{2} \mathrm{O}+\mathrm{CAd}+\mathrm{MWCNTs}\right]$ suspensions when the CAd/MWCNTs ratio was constant and equal to the optimal value (Figure 6a).

the amount of HPs, neither with the amount of MWCNTs. Similarly, the indirect tensile strength of $[\mathrm{PM}+\mathrm{CC}]$ and $[\mathrm{PM}+\mathrm{CC}+\mathrm{MWCNTS}]$ samples remain similar e independent of CC concentration and CC+MWCNTs (Figure 7b). Except for the samples with 0.6 wt\% of HPs and 1 wt\% MWCNTs, the average indirect tensile strength was $32 \%$ bigger than the average of the [PM] samples. However, suppose the amount of HPs increases to 1.8 wt\%, and MWCNTs increases to $3 \mathrm{wt} \%$. In that case, the average value of the indirect tensile strength is $16 \%$ bigger than the PM samples' average. Figure 7c shows the indirect tensile strength of the samples [PM], [PM+SNF], and [PM+SNF+MWCNTS] samples. The indirect tensile strength in the $[P M+S N F]$ samples decreases while the SNF amount increases. However, the indirect tensile strength in the [PM+SNF+MWCNTs] increases while the SNF+MWCNTS amount increases. 


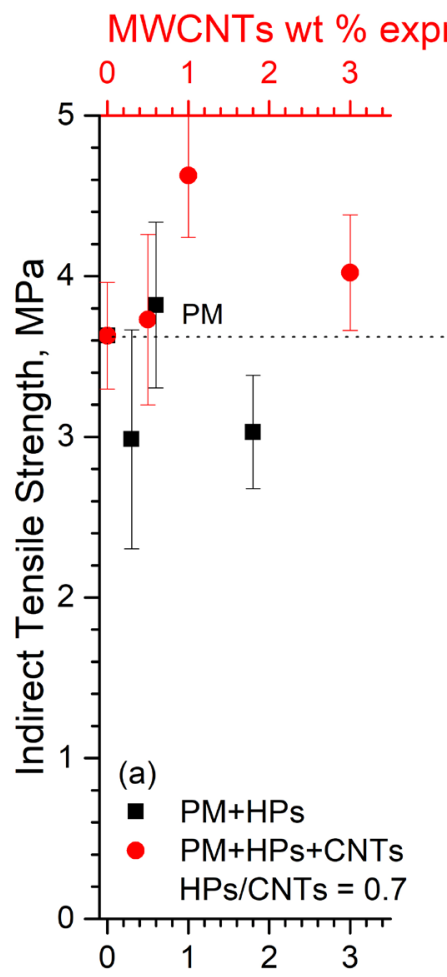

pressed as a cement weight percentage

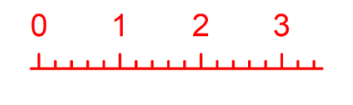

(b)

- $\mathrm{PM}+\mathrm{CC}$

- $\mathrm{PM}+\mathrm{CC}+\mathrm{CNTS}$ $\mathrm{CC} / \mathrm{CNTS}=0.6$ $\begin{array}{llll}0 & 1 & 2 & \end{array}$
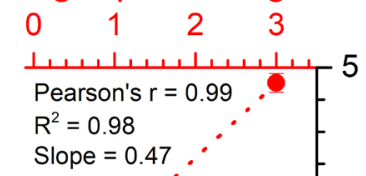

\section{5}

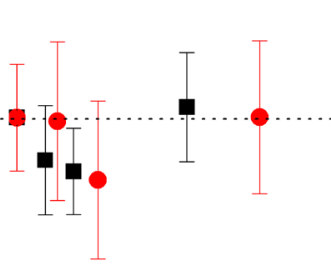

(x)
Figure 7. The indirect tensile strength of hardened concrete discs after seven days of curing and setting.
Figure 8 illustrates the applied load evolution over time until collapse occurs and during the indirect tensile test on [PM+SNF] and $[P M+S N F+M W C N T s]$ samples. The maximum load that the $[\mathrm{PM}+\mathrm{SNF}]$ samples can stand before the collapse decreases in inverse proportion with SNF. Thus, the SNF has a deleterious effect on the HE cement-mortar samples. In contrast, the indirect tensile strength of the [PM+SNF+MWCNT] samples increased as the amount of SNF and MWCNT increased, and samples show and reinforcement effect on the HE cement-mortar.

The zoomed-in images in Figure 8 highlight a loss in curve tendency to change smoothly. This marker is associated with the beginning of a crack. This marker also occurred in the test performed with [PM], but the disc's fracture occurred immediately. In contrast, in the disc reinforced with SNF and MWCNTS, fracture occurred after the elapse of a considerable time upon the fault had started. The time between the onset of failure and fracture increased with increasing amounts of SNF and MWCNTS.

Figure 9 shows the micrographs of wellconnected MWCNTs at the failure surface of the [PM+SNF+MWCNTs] sample. MWCNTs look like bridging different cement base materials units.

\section{Electrical conductivity}

The electrical conductivity as a function of time was measured when the applied voltage $V_{0}$ was equal to $30 \mathrm{~V}$. The elapsed time before resistivity stabilized was 5 min (Figure 10a). Thus, we measured the voltage $V$ between electrodes $B$ and $C$ and the current $/$ flowing through electrodes $A$ and $D$ after 5 min for various values of $V_{0}$ in [PM+CAd] samples (Figure 10b) and $[P M+C A d+M W C N T s]$ samples (Figure 10c). Figure 10b shows that the addition of CAd to the PM mixture decreases the electrical resistance (increase conductivity) of the [PM+CAd] mortar samples regardless of the CAd. While in Figure 10c, 


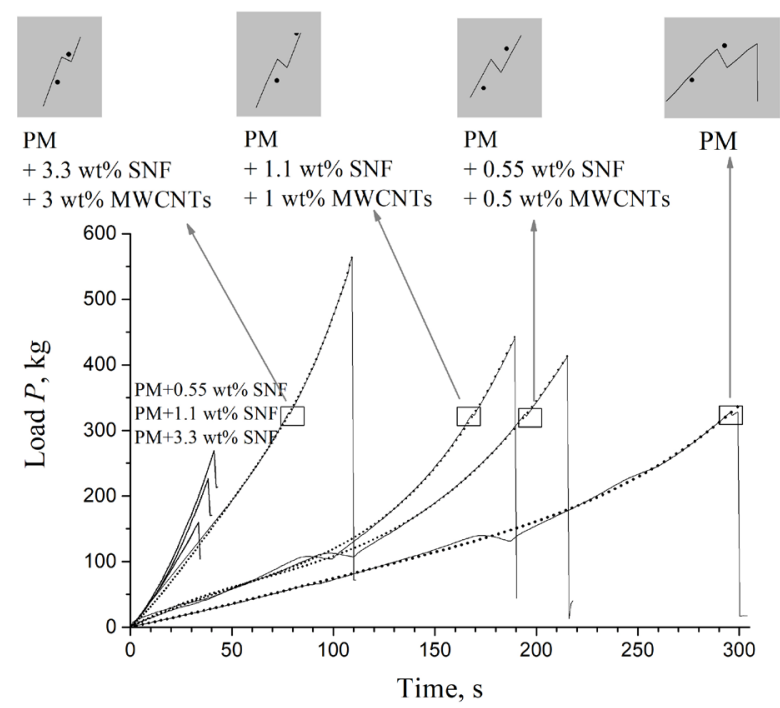

Figure 8 Evolution of the applied load overtime of $[\mathrm{PM}+\mathrm{SNF}+\mathrm{MWCNT}]$ samples during the Brazilian test.

it is apparent that the addition of HPs+MWCNTs to the PM mixture leads to samples with higher resistivity than the $[\mathrm{PM}]$ samples. However, the addition of CC+MWCNTs leads to samples with the smallest resistivity.

Figure 11 shows the electrical conductivity of [PM], [PM+CAd], and [PM+CAd+MWCNTs] samples. Symbols represent the mean value of three samples, and the vertical segments are the standard deviation. The mean value of the [PM] sample's electrical conductivity is $21 \times 10^{-6}$ $(\Omega \mathrm{cm})^{-1}$.

\section{DISCUSSION}

\section{Dispersion of multiwall carbon nanotubes in aqueous solution}

This study found that the CAd (SNF, HPs, and CC) for concrete are active in the UV-vis region in an aqueous solution $\left[\mathrm{H}_{2} \mathrm{O}+\mathrm{CAd}\right]$ (Figure $5 \mathrm{a}$ ). The three admixtures exhibit an absorption peak at $300 \mathrm{~nm}$. Moreover, the three solutions $\left[\mathrm{H}_{2} \mathrm{O}+\mathrm{CAd}+\mathrm{MWCNTS}\right]$ show similar behavior no matter the CAd and the fact that we used the $\left[\mathrm{H}_{2} \mathrm{O}+\mathrm{CAd}\right]$ as a blank (Figure $5 \mathrm{~b}$ ). There are

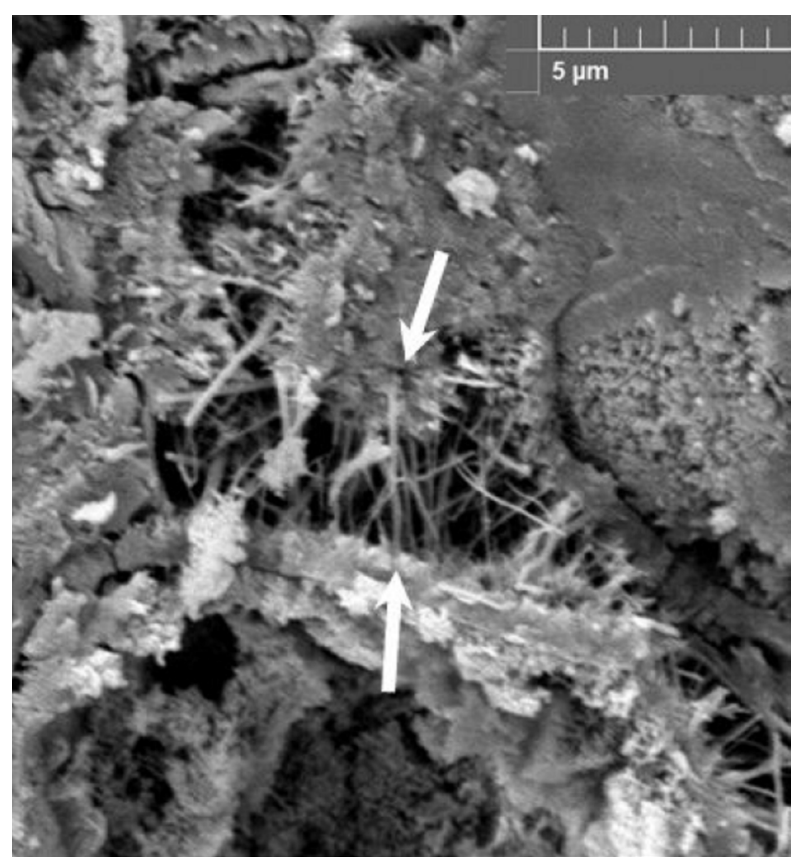

Figure 9. Micrograph of the failure surface of $[\mathrm{PM}+\mathrm{SNF}+\mathrm{MWCNT}]$ sample. The arrows indicate the links of MWCNT with the matrix material.

four possible contributors to the absorption spectrum: (1) free CAd, (2) free MWCNTs, (3) free [CAd+MWCNT], and (4) Mie scattering from CNTs agglomeration with a size comparable to the incident wavelength (Alafogianni et al. 2016). The blank correction with the $[\mathrm{H} 2 \mathrm{O}+\mathrm{CAd}]$ reduces the contribution to the spectrum of CAd's molecules free in solution. Free MWCNTs are unlikely in an aqueous solution after ultrasonication and enough CAd amount. Free big size CNTs agglomerations -around 300 nmare unlikely after proper ultrasonic processing. In any case, the Mie scattering effect decreases the net absorption. It does not compromise the use of the absorption spectrum as a tool for dispersion quality control. Therefore, the main contributor to the spectrum comes from free $[C A d+M W C N T]$ in solution. Results in figure $5 \mathrm{~b}$ are in agreement with previous reports by (Zheng et al. 2019). Zheng et al. (2019) used similar MWCNTs from the same provider. They reported a characteristic peak at $300 \mathrm{~nm}$. Li \& 

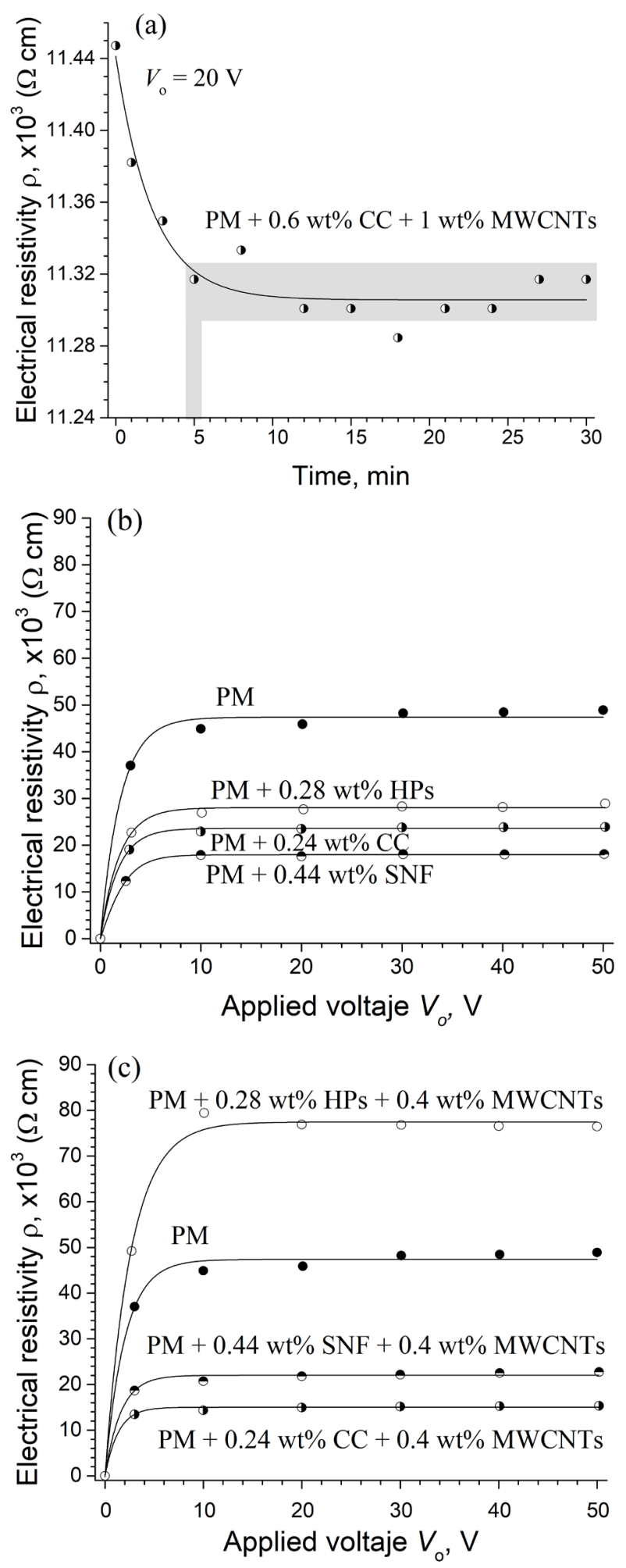

Figure 10. (a) The elapsed time before resistivity stabilized. (b) Effects of chemical admixtures on the electrical conductivity of PM. (c) Effects of CAd+MWCNTs on the electrical conductivity of PM.
Lin (2019) reported a characteristic peak around $250 \mathrm{~nm}$ while using MWCNTs with similar lengths and a half diameter. This result hints that the peak position depends mainly on the diameter of the CNTs, as predicted by Kataura et al. (1999). The verification of this hypothesis could lead to a convenient tool for controlling CNTs' diameter distribution.

The UV-vis spectra of all solutions exhibited a sharp peak from optical resonances in CNTs arising from excitons (Wang et al. 2005). At first, the community thought that these optical resonances arise from transitions between van Hove singularities in the valence and conductive bands of the nanotube's electronic density of states (Blanch et al. 2010). Therefore, the intensity of absorbance is related to the concentration of MWCNTs in suspensions according to the Lambert-Beer' law. Results in figure $5 b$ suggest that the adsorption of CAd on MWCNTs leads to the complex [CAd+MWCNT] that is responsible for the stabilization of the dispersion. It includes a weak physical absorption of CAd molecules on the CNTS' surfaces by either hydrophobic interaction, Coulombic attraction, or $\pi-\pi$ stacking interaction (Dassios et al. 2015). Our study considered that the complex [CAd+MWCNT] does not include chemical absorption because it perturbs the CNTs' electronic structure, potentially changing the characteristic peak wavelength.

Similarly, the absorbance at the peak specific wavelength is related to the degree of de-bundling of CNTs (Alafogianni et al. 2016), CAd concentration, and the energy needed for CNTS de-bundling. However, the dispersion capability of CAd depends on their concentration and an optimum CAd / MWCNTs ratio (Parveen et al. 2013). Besides concentration, the CAd type -nonionic, anionic, cationic, and amphoteric- and its structure significantly influence the dispersion 


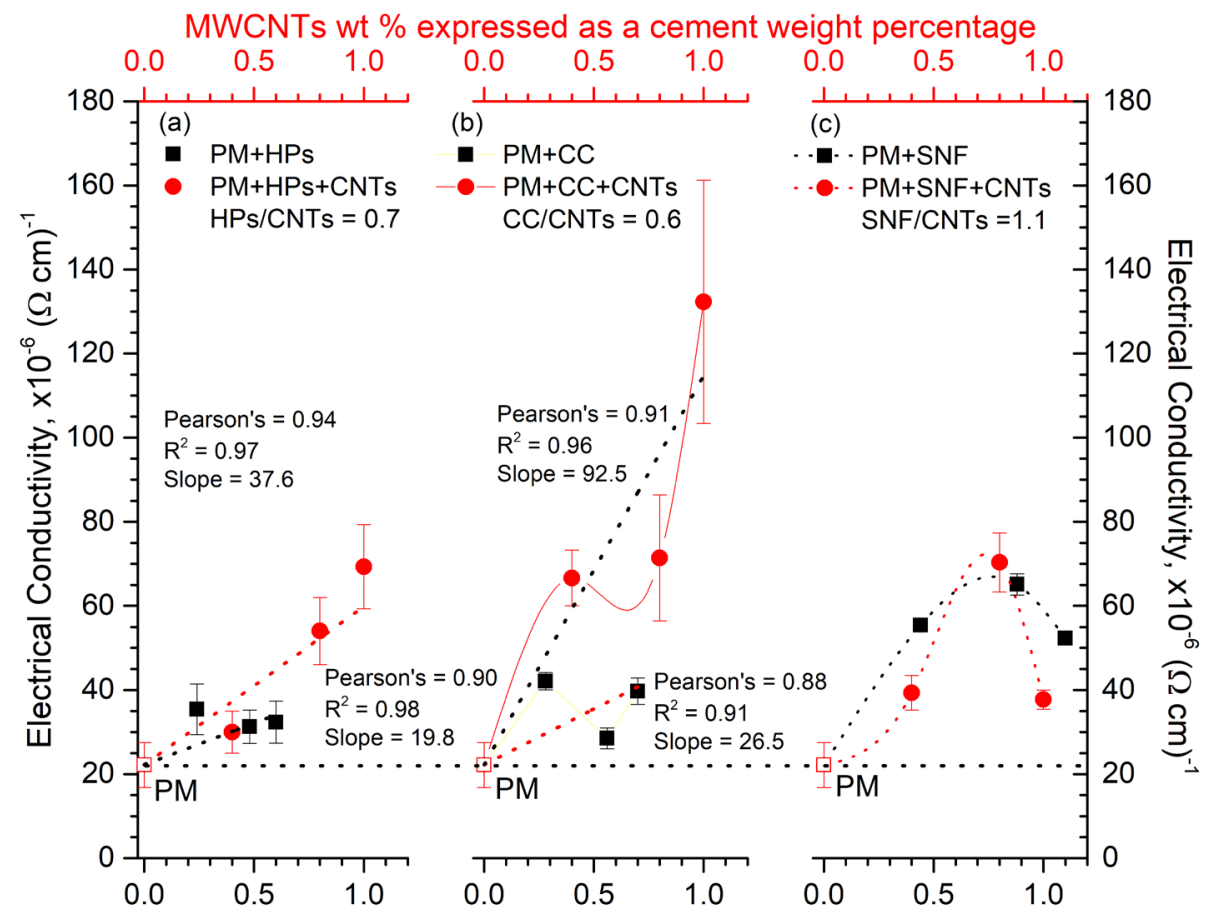

Chemical admixture wt \% expressed as a cement weight percentage
Figure 11. The electrical conductivity of [PM], [PM+CAd], and [PM+CAd+MWCNTs] samples. (a), (b), and (c) show the conductivity of samples prepared with HPs, CC, and SNF, respectively. of MWCNTs in water and subsequently within cement-based composites (Parveen et al. 2013).

We found that the CAd/MWCNT ratio for SNF, HPs, and CC was 1.1, 0.7, and 0.6, respectively (Figure 6a). Thus, the HPs (nonionic) and CC (amphoteric) compounds have more dispersion power than SNF (anionic). The optimal CAd/ MWCNT ratio is important because the dispersion's outcome strongly depends on the actual ratio value being below or above this umbral ratio. Suppose that the actual CAd/ MWCNT ratio is above the optimal ratio. In that case, the dispersion rate of the MWCNTs will increase at the beginning, and the minimum energy required to achieve the maximum dispersion decrease. Under these conditions, the excess CAd is free in the suspension, leading to the flocculation of the MWCNTs, likely through attractive depletion interaction (Blanch et al. 2010, Rastogi et al. 2008). Suppose that the actual CAd/MWCNT loading ratio is below the optimal ratio. In that case, the reverse effect occurs, and the required energy rise. However, under certain circumstances, it is impossible to achieve the maximum dispersion; for example, in suspensions with large amounts of MWCNTs, the optimal amount of CAd required may exceed the critical micelle concentration (Islam et al. 2003). Furthermore, enough CAd is required to produce a good coating of the surface of the MWCNTs and prevent re-aggregation (Yu et al. 2007).

Similarly, we found the minimum energy required for the full dispersion of MWCNTs when SNF, HPs, and CC were $270 \mathrm{~J} / \mathrm{ml}, 150 \mathrm{~J} / \mathrm{ml}$, and $150 \mathrm{~J} / \mathrm{ml}$, respectively (Figure 6b). The minimum energy required for optimal dispersion agrees with the trend observed for SNF, HPS, and CC'S dispersion power. The energy delivered to the system $\left[\mathrm{H}_{2} \mathrm{O}+\mathrm{CAd}+\mathrm{MWCNTS}\right]$ could produce two effects: the deagglomeration of the MWCNTs and the other being fragmentation of individual CNTS (Zheng et al. 2019). Energy above the optimal value affects the integrity of the MWCNTs, 
generates defects, and alters their length distribution (Chen et al. 2014) and subsequently within cement-based composites. Similarly, the delivery of energy below the optimal value leads to a low level of disaggregation of MWCNTs and generates defects within cement-based composites.

One interesting finding is that CNTs characteristic peak is not affected by the CAd nature -SNF (anionic), HPS (nonionic), and CC (amphoteric). Thus this result suggests that the characteristic peak is due to the photon interaction with MWCNT. Furthermore, this allowed the CAd/MWNT ratio determination and the minimum energy for optimal dispersion. These results further support the idea that ultrasound energy drives the disentanglement of CNTs boundless. Also, CNTs disperse via CAd adsorption, thermodynamically driven by CAd concentrations (Alvarez-Primo et al. 2019).

\section{Indirect tensile strength}

The results of this study indicate that the indirect tensile strength of [PM+SNF] samples decreased with the SNF concentration (Figure 7c). However, in [PM+SNF+MWCNTs] samples, the indirect tensile strength variation pattern changed and increased as a function of MWCNTS concentration. The other samples' indirect tensile strength remains approximately the same with or without HPS, CC, or MWCNTs (Figure $7 \mathrm{a}$ and $7 \mathrm{~b})$.

One finding is that the SNF is incompatible with cement-type HE. This result further supports the idea of at the beginning of cement hydration, $\mathrm{C}_{3} \mathrm{~A}$ is the most reactive phase in the fresh [PM+SNF] samples. The $\mathrm{C}_{3} A$ surface adsorbs a large amount of SNF. It delays the reaction of $\mathrm{C}_{3} \mathrm{~A}$ with sulfate and hinders the early strength development of the cement type HE (de Bem et al. 2018, Giraudeau et al. 2009, Pott et al. 2020, Ramachandran et al. 2002b, Yoshioka et al. 2002).
The SNF superplasticizer can also interfere and delay the $\mathrm{C}_{3} \mathrm{~S}$ and $\mathrm{C}_{2} \mathrm{~S}$ hydration, even though less often and less pronounced than the reaction with $C_{3} A$. Besides, SNF's molecule retards the dissolution between water and $\mathrm{Ca}^{2+}$ in the cement-solution interface, inhibiting nucleation and creating $\mathrm{Ca}^{2+}$ components (de Bem et al. 2018).

Another finding is that if SNF adsorption onto the surface of MWCNTS occurs first, the retarding effect of the SNF in the cement type HE does not show up. Moreover, the early development of strength in the [PM+SNF+MWCNTs] sample is enabled (Figure 7c). The SNF is a high-range water-reducing superplasticizer and an anionic compound that carry a negative charge on their hydrophilic head. Previous reports suggested that superplasticizer molecules like SNF work through weak physical adsorption on the MWCNTs surface by $\pi-\pi$ stacking interaction. Thus, the molecules wrap themselves around the MWCNT, given them a highly negative charge, so they repel each other in an aqueous solution. Upon hydration, they bound the MWCNT to the matrix. Therefore, the [PM+SNF+MWCNTS] indirect tensile strength increased as a function of MWCNTs concentration. The high Pearson correlation coefficient between the indirect tensile strength and the MWCNTs wt\% $(r=0.99)$ supports this result. The indirect tensile strength data fit a linear model with $\mathrm{R}^{2}=0.98$ and a slope of 0.47 (Figure 7c). Therefore, 2 wt \% of MWCNTs are needed to improve the indirect tensile strength in $1 \mathrm{MPa}$. However, the relative improvement will decrease as the design unconfined compression strength increase. Mainly due to the constant bond strength between the MWCNT and the cement matrix. More studies are needed to develop this idea further.

Thus, we found that the [PM+SNF+MWCNTS] indirect tensile strength improves 35\% compared to the [PM] samples at the 7 days. Similar results 
were reported by Evangelista et al. (2019), who reported an improvement of $27 \%$ at 7 days on the indirect tensile strength of MWCNTS reinforced ordinary Portland cement mortar composite. These results could imply that the SNF superplasticizers wrap themselves around the MWCNTs, leading to a mild improvement of the indirect tensile strength (mechanical properties). More studies are needed to confirm this hypothesis.

The results in Figure $7 \mathrm{~b}$ suggest that $\mathrm{CC}$ does not affect the indirect tensile strength of HE cement-mortar composites samples with and without MWCNTS. Although the CC accelerates the setting time and the early strength development, Ramachandran et al. (2002a) reported that this effect is marginal in the cement type HE. Thus, we do not observe any improvement or deleterious effect on the samples tested at seven days. The CC adsorption on the CNT surface involves weak physical adsorption on the CNTs' surfaces by Coulombic attraction. The CC's bonding effect is weak and does not improve the indirect tensile strength. This result reflects those of Skripkiunas et al. (2019). They also found that the density, flexural, and compressive strength of cement mortar modified by CC and MWCNT did not change significantly. Skripkiunas et al. ( 2019) did not identify new bonds and phases in the hardened cement paste modified by CC and MWCNT. Thus, Skripkiunas et al. (2019) concluded that the absence of new bonds and phases is related to the absence of improvement in mortars' physical properties.

Similarly, this study found that the HPS do not affect the HE cement-mortar composite sample's indirect tensile strength with and without MWCNTS (Figure 7a). The HPs is a waterreducing plasticizer and a nonionic compound that does not charge its hydrophilic head group. The HPs do not produce ions in an aqueous solution, and the steric effect prevents MWCNTs agglomeration. The HPs adsorption on the MWCNTs surface involves weak physical interaction on the CNTs' surface by hydrophobic interaction. Thus, the bonding effect of the HPs is weak and does not lead to an improvement in the indirect tensile strength.

\section{Evolution of the applied load over time}

This study found evidence of the MWCNTs' potential to control crack propagation phenomena (Figures 8 and 9). The enhancements in the indirect tensile strength of [PM+SNF+MWCNTS] samples are related to the bridging effect of MWCNTs across micro-cracks and pores. MWCNTs form a network (Figure 9) capable of enhancing load transmission capacity through the matrix. Moreover, nanotubes give additional strain capacity to the matrix by dissipating energy through multiple pulls out of nanotubes from the matrix before reaching a critical state (Figure 8). Rodriguez et al. (2017) reported similar results regarding the bridging effect of CNTs. Therefore, the ability of [PM+SNF+MWCNTS] samples to maintain their integrity after the crack initiation suggests an interplay between the MWCNTs and the hydrated products mediated by a strong bond (Figure 9). This bond is due to the nucleation of hydrate products ( $\mathrm{C}-\mathrm{S}-\mathrm{H})$ by the MWCNTs. Therefore, CNTS connect the hydrated products, enhancing the bridging effect between pores (Jeevanagoudar et al. 2017, Li \& Lin 2019). The micrograph in Figure 9 confirms that MWCNTs are distributed and are attached to the hydrated products. More studies are needed to analyze the interface between the surface of MWCNTs and the hydrate products in cement-based composites. The strength of the bonding determines the reinforcement effect of CNTS. 


\section{Electrical conductivity}

This study found that the electrical resistivity (The inverse of the conductivity) of the [PM], $[P M+C A d]$, and [PM+CAd+MWCNTs] samples stabilized after 5 min has elapsed (Figure 10a). The time of $5 \mathrm{~min}$ is similar to that found by D'Alessandro et al. (2016) for [PM+CAd+MWCNTs] samples. In general, the variation in resistivity within the first few minutes after the voltage is applied is mainly due to the materials' dielectric properties exhibiting a polarization effect. The polarization effect depends on CAd, MWCNTs, water, and ion contents in the material's matrix and the temperature, among others (Han et al. 2011).

Another finding is that HPS, CC, and SNF decreased the electrical resistivity in the $[\mathrm{PM}+\mathrm{CAd}]$ samples (Figure $10 \mathrm{~b}$ ). This result suggests that the electrical resistivity of the CAd is lower than the PM. This finding agrees with Chung's conclusion that the electrical conductivity of CBM is governed by (1) the degree of admixture dispersion, (2) the contact electrical resistivity of the interface between the admixture and the cement matrix, and (3) the admixture itself (Chung 2004). Thus, the mortar electrical resistance is affected by CAd electrical conductivity and ions in the matrix.

In contrast, when using small amounts of CAd and MWCNTs, the tendency to reduce the resistivity depended on the CAd (Figure 10c). Thus, this study found that CC and MWCNTS cause [PM+CC+MWCNTs] samples electrical conductivity to increase significantly (507\%) compared with the conductivity of [PM] samples (Figure 11b). The electrical conductivity of the [PM+CC+MWCNTs] samples increased as a function of MWCNTs concentration. The high Pearson correlation coefficient between the electrical conductivity and the MWCNTs wt\% $(r=0.91)$ supports this result. The electrical conductivity data fit a linear model with $\mathrm{R}^{2}=0.96$ and a slope of 92.5 (Figure 11b). In contrast, there were mild increases in electrical conductivity of [PM+HPS+MWCNTS] and [PM+SNF+MWCNTS] samples (Figures 11a and 11c).

Many factors affect the electrical conductivity of MWCNTs cement mortar composites. Intrinsic factors like water/cement ratio, aging, pore structure, CAd and CNTs electrical conductivity, CAd and CNTs concentration, and the degree of MWCNTs dispersion. Also, the transition zone between the cement paste and the aggregate or CNTs might enhance the conductivity (Chung 2004). Extrinsic factors affect the electrical conductivity measurements, including specimen geometry, moisture content, temperature, and electrode spacing (Azarsa \& Gupta 2017). This study keeps the water/cement ratio constant and measures the electrical conductivity seven days after preparation. The porous structure is one of the main parameters affecting the electrical resistivity in CBM (Dalla et al. 2019).

However, Skripkiunas et al. (2019) show that in a cement mortar modified by MWCNT and $\mathrm{CC}$ in the amount $2 \%$ by weight, the total pore volume per unit volume decreased by $2.1 \%$.

Additionally, the open capillary porosity increased by $1.6 \%$. Thus, the CC did not affect the pore structure of the samples significantly. However, the results in Figure 10b show that the $[\mathrm{PM}+\mathrm{CC}]$ electrical conductivity is higher than the $[P M]$, suggesting that the conductivity of CC es higher. Figure 10b shows that the electrical conductivity of the [PM+CC+MWCNTs] is even higher than the $[\mathrm{PM}+\mathrm{CC}]$ and $[\mathrm{PM}]$. One explanation is that the electrical conductivity of the MWCNTs $\left(10^{5} \mathrm{~s} / \mathrm{m}\right)$ is many orders of magnitude higher than the conductivity of the [PM] $\left(2 \times 10^{-3} \mathrm{~S} / \mathrm{m}\right)$ and the $[\mathrm{PM}+\mathrm{CC}]\left(5 \times 10^{-3} \mathrm{~S} / \mathrm{m}\right)$. This contrast supports the fact that electron transport in [PM+CC+MWCNTs] samples occurs through an MWCNTs network in the matrix, consisting of dispersed MWCNTs (Jang et al. 
2016). In particular, electrical conductivity increases by the electrical tunneling between adjacent MWCNTs and, consequently, depends on the tunneling gap and the cement matrix's conductivity (Yoo et al. 2019). Nevertheless, MWCNTs behave as non-conductive inclusions when their mutual distances are high. When the MWCNTS concentration increases above the percolation level and their mutual distances decrease, nanotubes interactions dominate the composite's electrical conductivity (D'Alessandro et al. 2016). Figure 10b shows that [PM+CC+MWCNTs] ' electrical conductivity suddenly increased when the CNTs concentration went from 0.7 to $1 \mathrm{wt} \%$, suggesting that the MWCNTs percolation level is around 0.7 wt \%. Therefore, before the CNTs reach a concentration of 0.7 wt \%, conductivity is governed by CC; when the CNTs concentration is above $0.7 \mathrm{wt}$ $\%$, MWCNTs govern the conductivity. Therefore, the conductivity of HE cement mortar can be improved by incorporating CC and MWCNTs. However, to the best of the authors' knowledge, there is no published study regarding the electrical resistivity of HE cement-CC-MWCNTS mortar composites. A note of caution is due here since chloride diffusivity compromise durability. The chloride threshold establishes a limit for the chloride ion in the matrix (Dalla et al. 2019, Abd El Fattah et al. 2020). Further study is still needed to understand CC and MWCNTS interaction to make conductive MWCNT- HE cement-based composite practical.

\section{CONCLUSIONS}

This study used three available commercial CAds used for concrete: (1) HPs based water-reducing plasticizer, (2) SNF-based superplasticizer, and (3) CC-based accelerating agent. The three CAds dispersed MWCNTs in an aqueous solution.
Ultrasonication and the optical absorption spectroscopy allowed the determination of optimal CAd/MWCNTs loading ratio and minimal energy for optimal CNTs dispersion. The MWCNTS dispersion occurs by the combined effect of ultrasonication energy and CAd adsorption on the nanotube surface.

The HPs based water-reducing plasticizer and the CC-based accelerating agent are compatible with HE cement. In contrast, the SNF-based superplasticizer is incompatible with the HE cement. The indirect tensile strength decreased when the SNF concentration increased.

HPS and CC's adsorption on the MWCNTS surface disperse CNTs in aqueous solution via repulsive interaction among [HPS+MWCNTS] and [CC+MWCNTs] complexes. While the limited interference of [HPS+MWCNTS] and [CC+MWCNTS] complexes on the hydration of the HE cement particles do not improve or damage the indirect tensile strength of CNTs reinforced CBM.

The adsorption of SNF-based superplasticizer on the MWCNTs surface disperses CNTs in aqueous solution via repulsive interaction among [SNF+MWCNTS] complexes. While the interference of [SNF+MWCNTS] complexes on the HE cements particles' hydration improves, the indirect tensile strength of CNTs reinforces CBM.

The addition of HPS, CC, SNF based CAd to the PM mixture decreases the electrical resistance (increase conductivity) of the [PM+CAd] mortar samples regardless of the CAd.

The adsorption of the CC-based accelerating agent on the MWCNTs surface favors a substantial improvement in the electrical conductivity of CNTs reinforced CBM composite. The results suggest that the [CC+MWCNTs] conductivity governs the electrical conductivity of [PM+CC+MWCNTS] composite. Moreover, further studies should verify if, below the 
threshold concentration of [CC+MWCNTs] complexes, the CAd's ionic contribution governs the composite's conductivity. While above the threshold concentration of [CC+MWCNTs] complexes, the CNTs' conductivity controls the composite's conductivity through closer CNT electrical tunneling. Therefore, engineering the [CAd+MWCNTs] complexes' electrical properties could improve [PM+CAd+MWCNTs] composites' electrical conductivity properties. More studies are needed to know how the [CAd+MWCNTs] complexes' properties control the improvement of the $[\mathrm{PM}+\mathrm{CAd}+\mathrm{MWCNTs}]$ composite properties.

\section{Acknowledgments}

The authors express their gratitude to the Prometheus Project of the Secretary of Higher Education, Science, Technology and Innovation of the Republic of Ecuador (Proyecto Prometeo de la Secretaria Superior, Ciencia, Tecnología e Innovación de la República del Ecuador. The Technical University of Loja, Ecuador, provided financial support through the project [PROY_GMIC_1142].

\section{REFERENCES}

ABD EL FATTAH A, AL-DUAIS I, RIDING K, THOMAS M, AL-DULAIJAN S \& AL-ZAHRANI M. 2020. Field validation of concrete transport property measurement methods. Materials 13(5): 1-19. https://doi.org/10.3390/ma13051166.

ALAFOGIANNI P, DASSIOS K, FARMAKI S, ANTIOHOS SK, MATIKAS TE \& BARKOULA NM. 2016. On the efficiency of UV-Vis spectroscopy in assessing the dispersion quality in sonicated aqueous suspensions of carbon nanotubes. Colloids Surfaces A: Physicochem Eng Asp 495: 118-124. https://doi.org/10.1016/j.colsurfa.2016.01.053.

ALAFOGIANNI P, DASSIOS K, TSAKIROGLOU CD, MATIKAS TE \& BARKOULA NM. 2019. Effect of CNT addition and dispersive agents on the transport properties and microstructure of cement mortars. Constr Build Mater 197: 251-261. https:// doi.org/10.1016/j.conbuildmat.2018.11.169.

ALVAREZ-PRIMO F, KUMAR SA, MANCIU FS \& JODDAR B. 2019. Fabrication of surfactant-dispersed HiPco single-walled carbon nanotube-based alginate hydrogel composites as cellular products. Int J Mol Sci 20(19): 1-17. https://doi. org/10.3390/ijms20194802.
AZARSA P \& GUPTA R. 2017. Electrical Resistivity of Concrete for Durability Evaluation: A Review. Adv Mater Sci Eng 2017: 1-30. https://doi.org/10.1155/2017/8453095.

BAUTISTA-GUTIERREZ KP, HERRERA-MAY AL, SANTAMARÍALÓPEZ IM, HONORATO-MORENO A \& ZAMORA-CASTRO SA. 2019. Recent progress in nanomaterials for modern concrete infrastructure: Advantages and challenges. Materials 12(21): 1-40. https://doi.org/10.3390/ma12213548.

BLANCH AJ, LENEHAN CE \& QUINTON JS. 2010. Optimizing surfactant concentrations for dispersion of single-walled carbon nanotubes in aqueous solution. J Phys Chem B 114(30): 9805-9811. https://doi.org/10.1021/jp104113d.

CAMPILLO I, DOLADO JS \& PORRO A. 2003. Highperformance nanostructured materials for construction, nanotechnology in construction. In: $1^{\text {st }}$ International Symposium on Nanotechnology in Construction, Paisley, Scotland: Royal Society of Chemistry, London, p. 219-223.

CARMONA S \& AGUADO A. 2012. New model for the indirect determination of the tensile stress-strain curve of concrete by means of the Brazilian test. Mater Struct 45: 1473-1485. https://doi.org/10.1617/s11527-012-9851-0.

CHEN SJ, COLLINS FG, MACLEOD AJN, PAN Z, DUAN WH \& WANG CM. 2011. Carbon nanotube-cement composites: A retrospect. IES J Part A Civ Struct Eng 4(4): 254-265. https://doi.org/10.1080/19373260.2011.615474.

CHEN SJ, ZOU B, COLLINS F, ZHAO XL, MAJUMBER M \& DUAN WH. 2014. Predicting the influence of ultrasonication energy on the reinforcing efficiency of carbon nanotubes. Carbon 77: 1-10. https://doi.org/10.1016/j.carbon.2014.04.023.

CHUNG DDL. 2004. Electrically conductive cement-based materials. Adv Cem Res 16(4): 167-176.

D'ALESSANDRO A, RALLINI M, UBERTINI F, MATERAZZI AL \& KENNY JM. 2016. Investigations on scalable fabrication procedures for self-sensing carbon nanotube cement-matrix composites for SHM applications. Cem Concr Compos 65: 200-213. https://doi.org/10.1016/j. cemconcomp.2015.11.001.

DALLA PT, TRAGAZIKIS IK, EXARCHOS DA, DASSIOS KG, BARKOULA NM \& MATIKAS TE. 2019. Effect of carbon nanotubes on chloride penetration in cement mortars. Appl Sci 9(5): 19-22. https://doi.org/10.3390/app9051032.

DASSIOS KG, ALAFOGIANNI P, ANTIOHOS SK, LEPTOKARIDIS C, BARKOULA NM \& MATIKAS TE. 2015. Optimization of sonication parameters for homogeneous surfactant assisted dispersion of multiwalled carbon nanotubes in aqueous solutions. J Phys Chem C 119(13): 7506-7516. https://doi.org/10.1021/acs.jpcc.5b01349. 
DE BEM DH, LIMA DPB \& MEDEIROS-JUNIOR RA. 2018. Effect of chemical admixtures on concrete's electrical resistivity. Int J Build Pathol Adapt 36(2): 174-187. https://doi. org/10.1108/IJBPA-11-2017-0058.

DEMARCHI D \& TAGLIAFERRO A. 2015. Carbon for Sensing Devices. In: Demarchi D \& Tagliaferro A (Eds). New York: Springer Cham Heidelberg, p. 112-114.

DODSON VH. 1990. Concrete Admixtures. New York: Springer Science \& Business Media, p. 73-89.

ERARSLAN N, LIANG ZZ \& WILLIAMS DJ. 2012. Experimental and numerical studies on determination of indirect tensile strength of rocks. Rock Mech Rock Eng 45: 739-751. https://doi.org/10.1007/s00603-011-0205-y.

EVANGELISTA ACJ, DE MORAIS JF, TAM V, SOOMRO M, DI GREGORIO L \& HADDAD AN. 2019. Evaluation of carbon nanotube incorporation in cementitious composite materials. Materials 12(9): 1-18. https://doi.org/10.3390/ ma12091504.

GARCÍA VJ, MÁRQUEZ CO, ZÚÑIGA-SUÁREZ AR, ZUÑIGA-TORRES BC \& VILLALTA-GRANDA LJ. 2017. Brazilian Test of Concrete Specimens Subjected to Different Loading Geometries: Review and New Insights. Int J Concr Struct Mater 11(2): 343-363. https://doi.org/10.1007/s40069-017-0194-7.

GIRAUDEAU C, D'ESPINOSE DE LACAILLERIE JB, SOUGUIR Z, NONAT A \& FLATT RJ. 2009. Surface and intercalation chemistry of polycarboxylate copolymers in cementitious systems. J Am Ceram Soc 92(11): 2471-2488. https://doi. org/10.1111/j.1551-2916.2009.03413.x.

GROSSIORD N, REGEV O, LOOS J, MEULDIJK J \& KONING CE. 2005. Time-dependent study of the exfoliation process of carbon nanotubes in aqueous dispersions by using UV-visible spectroscopy. Anal Chem 77(16): 5135-5139. https://doi.org/10.1021/ac050358j.

HAN B, GUAN X \& OU J. 2007. Electrode design, measuring method and data acquisition system of carbon fiber cement paste piezoresistive sensors. Sensors Actuat A-Phys 135(2): 360-369. https://doi.org/10.1016/j. sna.2006.08.003.

HAN B, YU X \& OU J. 2011. Multifunctional and smart carbon nanotube reinforced cement-based materials. In: Gopalakrishnan K et al. (Eds), Nanotechnology in Civil Infrastructure: A Paradigm Shift. Berlin Heidelberg: Springer-Verlag, p. 1-47.

HAN M ET AL. 2020. Graphitic multi-walled carbon nanotube cathodes for rechargeable Al-ion batteries with welldefined discharge plateaus. J Power Sources 451: 227769. https://doi.org/10.1016/j.jpowsour.2020.227769.
HAWREEN A \& BOJAS JA. 2019. Creep, shrinkage and mechanical properties of concrete reinforced with different types of carbon nanotubes. Constr Build Mater 198: 70-81.

HILDING J, GRULKE EA, ZHANG ZG \& LOCKWOOD F. 2003. Dispersion of Carbon Nanotubes in Liquids. J Dispers Sci Technol 24(1): 1-41. https://doi.org/10.1081/DIS-120017941.

HUNASHYAL AM, SUNDEEP GV, UADRI SS \& BANAPURMATH NR. 2011. Experimental investigations to study the effect of carbon nanotubes reinforced in cementbased matrix composite beams. Proceedings of the Institution of Mechanical Engineers, Part N: J Nanomater Nanoeng Nanosyst 225(1): 17-22. https://doi. org/10.1177/1740349911418570.

IIJIMA S. 1991. Helical microtubes of graphitic carbon. Nature 354: 56-58.

ISLAM MF, ROJAS E, BERGEY DM, JOHNSON AT \& YODH AG. 2003. High weight fraction surfactant solubilization of singlewall carbon nanotubes in water. Nano Lett 3: 269-273. https://doi.org/10.1021/nl025924u.

JAGDALE P, CHIOLERIO A, NADERI A, ROPPOLO I, RATTALINO I \& TAGLIAFERRO A. 2015. MWCNT polymer nanocomposites for piezoresistivity and percolation-principles and applications. In: Demarchi D \& Tagliaferro A (Eds), Carbon for Sensing Devices. New York: Springer Cham Heidelberg, p. 207-224.

JANG SH, KAWASHIMA S \& YIN H. 2016. Influence of carbon nanotube clustering on mechanical and electrical properties of cement pastes. Materials 9: 1-11. https:// doi.org/10.3390/ma9040220.

JEEVANAGOUDAR YV, KRISHNA RH, GOWDA R, PREETHAM R \& PRABHAKARA R. 2017. Improved mechanical properties and piezoresistive sensitivity evaluation of MWCNTS reinforced cement mortars. Constr Build Mater 144: 188194. https://doi.org/10.1016/j.conbuildmat.2017.03.139.

KATAURA H, KUMAZAWA Y, MANIWA Y, UMEZU I, SUZUK S, OHTSUKA Y \& ACHIBA Y. 1999. Optical properties of singlewall carbon nanotubes. Synth Met 103: 2555-2558.

KONSTA-GDOUTOS MS \& AZA CA. 2014. Self sensing carbon nanotube (CNT) and nanofiber (CNF) cementitious composites for real time damage assessment in smart structures. Cem Concr Compos 53: 162-169. https://doi. org/10.1016/j.cemconcomp.2014.07.003.

KONSTA-GDOUTOS MS, METAXA ZS \& SHAH SP. 2010. Highly dispersed carbon nanotube reinforced cement based materials. Cem Concr Res 40: 1052-1059. https://doi. org/10.1016/j.cemconres.2010.02.015. 
KOWALD T, TRETTIN R, DORBAUM N, STADLER T \& JIAN X. 2008. Influence of carbon nanotubes on the micromechanical properties of a model system for ultra-high performance concrete. In: Fehling et al. (Eds), $2^{\text {nd }}$ International Symposium on Ultra High Performance Concrete. Kassel, Germany: Kassel University press, p. 129-134.

KURDOWSKI W. 2014. Cement and Concrete Chemistry. New York: Springer Dordrecht Heidelberg, p. 60-65. https:// doi.org/10.1017/CBO9781107415324.004.

LI GY, WANG PM \& ZHAO XH. 2005. Mechanical behavior and microstructure of cement composites incorporating surface-treated multi-walled carbon nanotubes. Carbon 43: 1239-1245. http://dx.doi.org/10.1016/j. carbon.2004.12.017.

LI Y \& LIN H. 2019. Experimental study on the effect of different dispersed degrees carbon nanotubes on the modification of magnesium phosphate cement. Const Build Mater 200: 240-247. https://doi.org/10.1016/j. conbuildmat.2018.12.113.

LUSHNIKOVA A \& ZAOUI A. 2017. Improving mechanical properties of $\mathrm{C}-\mathrm{S}-\mathrm{H}$ from inserted carbon nanotubes. J Phys Chem Solids 105: 72-80.

MAKAR JM \& CHAN GW. 2009. Growth of cement hydration products on single-walled carbon nanotubes. J Am Ceram Soc 92: 1303-1310. https://doi. org/10.1111/j.1551-2916.2009.03055.x.

MAKAR JM, MARGESON J \& LUH J. 2005. Carbon nanotube/ cement composites-early results and potential applications. In: $3^{\text {rd }}$ International Conference on Construction Materials: Performance, Innovations and Structural Implications. Vancouver: Canada, p. 1-10.

NTE-INEM. 2009. 155:2009 Cemento hidráulico, mezclado mecánico de pastas y morteros de consistencia plástica. Quito, Ecuador: Instituto Ecuatoriano de Normalización.

NTE-INEM. 2011. 2563:2011 Morteros. Evaluación previa a la construcción y durante la construcción de morteros para mampostería simple y reforzada. Quito, Ecuador: Instituto Ecuatoriano de Normalización.

PARVEEN S, RANA S \& FANGUEIRO R. 2013. A review on nanomaterial dispersion, microstructure, and mechanical properties of carbon nanotube and nanofiber reinforced cementitious composites. J Nanomater 2013, p. 1-19. https://doi.org/10.1155/2013/710175.

POTT U, JAKOB C, JANSEN D, NEUBAUER J \& STEPHAN D. 2020. Investigation of the incompatibilities of cement and superplasticizers and their influence on the rheological behavior. Materials 13: 977. https://doi.org/10.3390/ ma13040977.
RAMACHANDRAN VS, BEAUDOIN JJ \& DELGADO AH. 2002a. Accelerating Admixtures. In: Handbook of Thermal Analysis of Construction Materials. Norwich: William Andrew Publishing/Noyes, 189 p.

RAMACHANDRAN VS, BEAUDOIN JJ \& DELGADO AH. 2002b. Superplasticizing Admixtures. In: Handbook of Thermal Analysis of Construction Materials. Norwich: William Andrew Publishing/Noyes, 261 p.

RASHAD AM. 2017. Effect of carbon nanotubes (CNTS) on the properties of traditional cementitious materials. Constr Build Mater 153: 81-101. https://doi.org/10.1016/j. conbuildmat.2017.07.089.

RASTOGI R, KAUSHAL R, TRIPATHI SK, SHARMA AL, KAUR I \& BHARADWAJ LM. 2008. Comparative study of carbon nanotube dispersion using surfactants. J Colloid Interf Sci 328: 421-428. https://doi.org/10.1016/j.jcis.2008.09.015.

RIXOM R \& MAILVAGANAM N. 2001. Chemical Admixtures for Concrete, $3^{\text {rd }}$ ed., New York USA: Taylor \& Francis e-library, $593 \mathrm{p}$.

RODRÍGUEZ B, QUINTERO JH, ARIAS YP, MENDOZA-REALES OA, OCHOA-BOTERO JC \& TOLEDO-FILHO RD. 2017. Influence of MWCNT/surfactant dispersions on the mechanical properties of Portland cement pastes. J Physics Conf Ser 935 012014, p. 1-5. https://doi. org/10.1088/1742-6596/935/1/012014.

SÁEZ DE IBARRA Y, GAITERO JJ, ERKIZIA E \& CAMPILLO I. 2006. Atomic force microscopy and nanoindentation of cement pastes with nanotube dispersions. Phys Status Solidi (A) 203: 1076-1081. https://doi.org/10.1002/pssa.200566166.

SANCHEZ F \& SOBOLEV K. 2010. Nanotechnology in concrete - A review. Constr Build Mater 24(11): 2060-2071. https:// doi.org/10.1016/j.conbuildmat.2010.03.014.

SEDAGHATDOOST A \& BEHFARNIA K. 2018. Mechanical properties of Portland cement mortar containing multiwalled carbon nanotubes at elevated temperatures. Constr Build Mater 176: 482-489. https://doi.org/10.1016/j. conbuildmat.2018.05.095.

SEGAWA Y, ITO H \& ITAMI K. 2016. Structurally uniform and atomically precise carbon nanostructures. Nat Rev Mater 1: 1-14. https://doi.org/10.1038/natrevmats.2015.2.

SIDDIQUE R \& MEHTA A. 2014. Effect of carbon nanotubes on properties of cement mortars. Constr Build Mater 50: 116129. https://doi.org/10.1016/j.conbuildmat.2013.09.019.

SKRIPKIUNAS G, YAKOVLEV G, KARPOVA E \& NG PL. 2019. Hydration process and physical properties of cement systems modified by calcium chloride and multi-walled carbon nanotubes. Rev Rom Mater 49(1): 58-67. 
WANG B, HAN Y, PAN B \& ZHANG T. 2013. Mechanical and Morphological Properties of Highly Dispersed Carbon Nanotubes Reinforced Cement Based Materials. J Wuhan Univ Techol Mater 28: 82-87.

WANG BM, LIU S \& HAN Y. 2015. Research progress on carbon nanotubes reinforced cement-based materials. Key Eng Mater 629: 487-493. https://doi.org/10.4028/ www.scientific.net/KEM.629-630.487.

WANG F, DUKOVIC G, BRUS LE \& HEINZ TF. 2005. The optical resonances in carbon nanotubes arise from excitons. Science 308: 838-841. https://doi.org/10.1126/ science.1110265.

YOO DY, YOU I, ZI G \& LEE SJ. 2019. Effects of carbon nanomaterial type and amount on self-sensing capacity of cement paste. Measurement 134: 750-761. https://doi. org/10.1016/j.measurement.2018.11.024.

YOSHIOKA K, TAZAWA EI, KAWAI K \& ENOHATA T. 2002. Adsorption characteristics of superplasticizers on cement component minerals. Cement and Concrete Res 32: 15071513. https://doi.org/10.1016/S0008-8846(02)00782-2.

YU J, GROSSIORD N, KONING CE \& LOOS J. 2007. Controlling the dispersion of multiwall carbon nanotubes in aqueous surfactant solution. Carbon 45: 618-623. https://doi. org/10.1016/j.carbon.2006.10.010.

ZAIN FM, MAHMUD HB, ILHAM A \& FAIZAL M. 2002. Prediction of splitting tensile strength of high-performance concrete. Cement and Concrete Res 32: 1251-1258. https://doi. org/10.1016/S0008-8846(02)00768-8.

ZHENG T, XU N, KAN Q, LI H, LU C \& ZHANG P. 2019. Wet-Spinning Assembly of Continuous, Highly Stable Hyaluronic / Multiwalled Carbon Nanotube Hybrid Microfibers. Polymers 11: 867.

\section{How to cite}

GARCÍA VJ, MARQUEZ CO, ZÚÑIGA-SUÁREZ AR, ZÚÑIGA-TORRES BC \& RÍOSGÓNZALES PJ. 2021. Mechanical and electrical properties of MWCNTs high early strength cement - mortars composite: Dispersion of CNTs and effect of chemical admixtures. An Acad Bras Cienc 93: e20200924. DOI 10.1590/0001-3765202120200924.

Manuscript received on June 12, 2020;

accepted for publication on January 19, 2021

\section{VÍCTOR J. GARCíA ${ }^{1,2}$}

https://orcid.org/0000-0003-0557-5957

CARMEN O. MÁRQUEZ ${ }^{2,3}$

https://orcid.org/0000-0002-9462-8004

\section{ALONSO R. ZÚÑIGA-SUÁREZ ${ }^{1}$}

https://orcid.org/0000-0001-9867-0069

\section{BERENICE C. ZÚÑIGA-TORRES ${ }^{1}$}

https://orcid.org/0000-0002-2833-8412

PEDRO J. RÍOS-GÓNZALEZ ${ }^{1}$

https://orcid.org/0000-0002-3781-8194

${ }^{1}$ Universidad Técnica Particular de Loja, 110150, Loja, San Cayetano Alto, Calle París, Loja, 110150 Provincia de Loja, Ecuador

${ }^{2}$ Universidad Nacional de Chimborazo, Facultad de Ingeniería, Av. Antonio José de Sucre, Riobamba, 060150

Riobamba, Provincia de Chimborazo, Ecuador

${ }^{3}$ Universidad de Los Andes, La Hechicera,

Mérida, 5115, Estado Mérida, Venezuela

Correspondence to: Víctor Julio García.

E-mail:vgarcia@unach.edu.ec

\section{Author contributions}

Conceptualization, Formal analysis, Research, Methodology, Writing - revision and editing (VJG). Methodology, Formal analysis, Writing - revision and editing (COM). Research, Resources, Validation (ARZ). Research, Resources, Validation (BCZ). Methodology, Research, Validation (PJR).

\section{(cc) BY}

